NBER WORKING PAPER SERIES

\title{
MORTALITY AND SOCIOECONOMIC CONSEQUENCES OF PRESCRIPTION OPIOIDS: EVIDENCE FROM STATE POLICIES
}

\author{
Robert Kaestner \\ Engy Ziedan \\ Working Paper 26135 \\ http://www.nber.org/papers/w26135
NATIONAL BUREAU OF ECONOMIC RESEARCH 1050 Massachusetts Avenue
Cambridge, MA 02138
August 2019, Revised April 2020

We thank Jiajia Chen, Cuicui Song and Lu Yao for research assistance. The views expressed herein are those of the authors and do not necessarily reflect the views of the National Bureau of Economic Research.

NBER working papers are circulated for discussion and comment purposes. They have not been peer-reviewed or been subject to the review by the NBER Board of Directors that accompanies official NBER publications.

(C) 2019 by Robert Kaestner and Engy Ziedan. All rights reserved. Short sections of text, not to exceed two paragraphs, may be quoted without explicit permission provided that full credit, including (C) notice, is given to the source. 
Mortality and Socioeconomic Consequences of Prescription Opioids: Evidence from State

Policies

Robert Kaestner and Engy Ziedan

NBER Working Paper No. 26135

August 2019, Revised April 2020

JEL No. I12,I18

\begin{abstract}
This article presents estimates of the effects of state prescription opioid policies on prescription opioid sales, mortality and socioeconomic outcomes of adults. Results indicate that state implementation of a "modern" PDMP is associated with decreases in opioid sales of between 5\% and $20 \%$ and that pill mill laws are associated with a decrease in opioid sales of between $15 \%$ and $50 \%$. The reductions in prescription opioid sales associated with these state policies were, in general, not associated with statistically significant effects on mortality. In the case of socioeconomic outcomes, we found consistent evidence that the adoption of a "modern" PDMP was associated with small, but statistically significant reductions in employment of $1 \%$ to $2 \%$ across all demographic groups examined; small reductions in earnings that were not statistically significant and similarly small, marginally significant increases in receipt of public assistance, particularly for women; and a significant, but small (1\%) decline in the probability of being married among females. In contrast, pill mill laws were associated with marginally significant increases in employment of $1 \%$ to $2 \%$, but only among those ages 18 to 25; small, but insignificant increases in earnings of males of between $2 \%$ to $4 \%$; and a significant, but small (1\%) decline in the probability of being married among all demographic groups.
\end{abstract}

Robert Kaestner

Harris School of Public Policy

University of Chicago

1307 East 60th Street (Room 3057)

Chicago, IL 60637

and NBER

kaestner@uchicago.edu

Engy Ziedan

Tulane University

6823 St. Charles Avenue

206 Tilton Hall

New Orleans, LA 70118

eziedan@tulane.edu 


\section{Introduction}

The opioid epidemic is one of the most pressing public health issues for local, state and federal policymakers and its consequences have been widely documented. The epidemic is often characterized by the rise of prescription opioid use. Between 1992 and 2011, the number of opioid prescriptions in the U.S. increased nearly three-fold from approximately 75 million annually to 220 million annually (Manchikanti et al. 2017). At its peak in 2010-2012, the Opioid prescription rate was 80 per 100 persons in the U.S., although only about $20 \%$ of the population had one or more prescriptions (CDC 2017). Since 2010, the opioid prescription rate declined to 51 per 100 persons in 2018(CDC 2020). The second prominent fact used to characterize the opioid epidemic is the rise in prescription opioid-related mortality. Between 1999 and 2010, the rate of prescription opioid overdose deaths increased from just over 1 per 100,000 to just over 5 per 100,000 and remained at around 5 per 100,000 through 2016 (CDC 2018). Finally, the rise in non-prescription opioid (e.g., heroin and fentanyl) deaths are also often included to document the epidemic. The rate of non-prescription opioid (heroin and fentanyl combined) deaths increased from approximately 1 per 100,000 in 1999 to 2 per 100,000 in 2010. After this date, non-prescription opioid deaths began to increase markedly rising to 9 per 100,000 by 2017 (CDC 2019).

While the sheer magnitude of opioid prescriptions and the mortality consequences of the opioid epidemic have garnered most of the research and public policy attention, the rise in prescription opioid use may have had other serious consequences. For example, there have been a few studies of the effect of opioid use on employment, although evidence from these few studies remains mixed (Currie et al. 2018; Krueger 2017; Harris et al. 2017). Other outcomes that may be plausibly affected by opioid use, both medical and non-medical use, include marriage, earnings, and receipt of social welfare benefits (Duenas et al. 2016; Gustavsson et al. 2012; Turk et al. 2016). There have been no studies of the effect of prescription opioid use on these outcomes.

In this article, we add to this limited literature. We exploit plausibly exogenous variation in prescription opioid use caused by states’ adoption of Prescription Drug Monitoring Programs (PDMPs) and "pill mill” statutes. We show that the adoption of PDMPs that have been characterized as "modern" decreased all opioid prescription sales by between $5 \%$ to $10 \%$ and decreased sales of the top two prescriptions (hydrocodone and oxycodone) by between $7 \%$ and 20\%. Pill mill statutes had even larger effects; decreasing all opioid prescription sales by between $14 \%$ and $28 \%$ and decreased hydrocodone and oxycodone prescriptions by $20 \%$ to $48 \%$. This evidence is consistent with several prior studies. ${ }^{1}$ The variation in prescription opioid sales, and presumably opioid use, caused by the state policies provides

\footnotetext{
${ }^{1}$ See Finley et al. (2017) for a review. The evidence of the effect of PDMPs on opioid prescriptions is somewhat mixed. We present evidence below on their effectiveness and review other studies that show similar findings.
} 
exogenous variation in prescription opioid use that we use to assess the effects of prescription opioid use on socioeconomic outcomes. We also estimate the effect of these states policies on mortality.

An important conceptual and empirical contribution of our analysis is the stratification of the sample by age and gender. This stratification is motivated by evidence suggesting that most prescription opioid use is medical and that rates of non-medical use, and the ratio of non-medical to medical use of prescription opioids differs significantly by age, gender and to a lesser extent education (see Table 1). For example, approximately $15 \%$ of females ages 35 to 64 reported that they had a prescription opioid in 2002-2006, but only 3\% reported non-medical use. These figures suggest that this group of females has a relatively high rate of prescription opioid use that is mostly medically prescribed. There is relatively little purposeful misuse of prescription opioids, or use of illegal opioids, among this demographic group, and women in this age group have relatively little use of other illegal drugs (5\%) excluding marijuana. In contrast, among men ages 18 to 34, only 7\% reported having a medical prescription for opioids in 20022006, but $10 \%$ also reported non-medical use. For this group, much of prescription opioid use is misuse and this group has a relatively high rate of illegal drug use (17\%) excluding marijuana. Given these differences in opioid use, it is plausible that that changes in prescription opioid use due to state policies had different effects on mortality and socioeconomic outcomes of these demographic groups. We develop this point in more detail below.

As already noted, results of our analysis indicate that state implementation of a "modern" PDMP is associated with decreases in opioid sales of between $5 \%$ and $20 \%$ and that pill mill laws are associated with a decrease in opioid sales of between $15 \%$ and $50 \%$. The reductions in prescription opioid sales associated with these state policies were, in general, not associated with statistically significant effects on mortality. Nor were these policies associated with clinically meaningful changes in mortality, although for drug-specific causes of mortality we cannot reject small effect sizes. In the case of socioeconomic outcomes, we found consistent evidence that across all demographic groups the adoption of a "modern" PDMP was associated with small, but statistically significant reductions in employment of $1 \%$ to $2 \%$; small reductions in earnings that were not statistically significant and similarly small; marginally significant increases in receipt of public assistance, particularly for women; and a significant, but small (1\%) decline in the probability of being married among females. In contrast, pill mill laws were associated with marginally significant increases in employment of $1 \%$ to $2 \%$, but only among those ages 18 to 25; small, but insignificant increases in earnings of males of between $2 \%$ to $4 \%$; and a significant, but small (1\%) decline in the probability of being married among all demographic groups.

Overall, while state policies were associated with a substantial reduction in prescription opioid sales (and presumably use), the impact of this decline and these policies on mortality and socioeconomic outcomes has been quite modest at the population level. This is an important finding and policy relevant. 
However, population level estimates suggest that effects at the individual level may have been substantial because only a portion of the population was likely affected by the policy. We discuss these issues in our conclusion.

\section{State Responses to Opioid Epidemic}

Many states have responded to the opioid epidemic by enacting a variety of laws and policies related to controlling and monitoring opioid prescribing behavior. The most prominent state response has been the enactment, refinement and strengthening of Prescription Drug Monitoring Programs (PDMPs). PDMPs are widely seen as one of the most effective policies to deter opioid abuse. ${ }^{2}$ While PDMPs have been in existence for many years, with California establishing the first in 1939, there has been substantial activity in recent years to bolster the effectiveness of PDMPs. ${ }^{3}$ Between 2000 and 2016, 35 PDMPs were established. In addition, newly established PDMPs and upgrades to existing PDMPs differ from earlier PDMPs in that they are fully electronic, more accessible to physicians, pharmacists and other pertinent parties, and often include requirements for mandatory use.

To characterize state prescription opioid policies, we reviewed the range of policies and dates of implementation used in prior studies (e.g., Horwitz et al. 2018). Our goal was to accurately identify the timing of implementation of a policy and to classify in a parsimonious way main elements of state opioid policies. Based on our review, we chose six measures: four mutually exclusive categories of PDMP categories and an indicator for whether a state had a "pill mill” law. The most basic PDMP category identifies the date PDMP legislation was enacted. If enactment was contingent on the availability of funding, we used the date funding became available as the implementation date (Horwitz el al 2018). The next PDMP category identifies the date that an electronic PDMP was implemented. If the original PDMP that was enacted was also electronic, the former date is used. Electronic systems are not paper-based and allow the prescriber to transmit the prescription information electronically to the state authority (Manchikanti, Brown and Singh 2002). When the PDMP became accessible to any authorized user (e.g., physician, pharmacist, or member of law enforcement), we classified the PDMP as “modern” and used the date the modern PDMP was implemented. If the state implemented an electronic and modern system at same time then we used that date to classify the state as having a "modern” PDMP. The last category of PDMP represents the month and year that querying the (modern) PDMP database became mandated (Buchmueller and Carey 2018; Mallat; 2017). A mandated PDMP requires prescribers to check the state medication history database before prescribing controlled substances. In choosing the implementation

\footnotetext{
${ }^{2}$ https://www.cdc.gov/drugoverdose/pdmp/states.html, last accessed May 14, 2019.

3 http://www.pdmpassist.org/pdf/state_survey_comparisons_TAG_final_20161214_revised.pdf, last accessed May 14, 2019.
} 
dates for each PDMP category we verified the dates on several websites and followed Horwitz et al. (2018). If the date of implementation is mid-year, we use fractional time periods. For example, a state that has an electronic PDMP for half the year and a “modern” PDMP for half the year, a value 0.5 was assigned to each of these categories in that year.

Despite the prominence of PDMPS, states have also taken other steps to control prescription opioid use. One of the most important of these policies is regulations on "pill mills" (pain management clinics). Pill Mill laws target prescribers who account for a disproportionate share of opioid prescribing. Pill Mill laws include legal provisions establishing state inspection authority or specific training requirements for Pill Mill owners or associated physicians ${ }^{4}$. These laws are associated with a decrease in the number of pain management clinics (Gau et al 2017). In choosing the dates that best reflect when Pill Mill laws were activated, we followed Buchmueller and Carey (2018) and Malllatt (2017). ${ }^{5}$

Figure 1 shows changes over time in state PDMPs using a classification of PDMPs that we have adopted. As Figure 1 shows, there is variation over time within states in both the extensive margin, reflected in the creation of electronic PDMPs and adoption of pill mill laws, and at the intensive margin, reflected in significant changes in the structure of PDMPs as reflected in the growth of what we refer to as “modern” PDMPs.

\section{Evidence of the Effectiveness of Prescription Drug Monitoring Programs}

As noted, PDMPs are widely viewed as an effective tool to combat opioid abuse. Supporting this view is evidence from an existing literature. A recent, comprehensive literature review by Weiner et al. (2017) concluded that PDMPs have effectively reduced opioid prescribing emphasizing the point that it is particular features of a PDMP, such as mandatory use and greater integration of the PDMP into electronic health records that are particular effective.

There are several, quasi-experimental studies of the effect of PDMPs on opioid prescriptions. ${ }^{6}$ Bao et al. (2016) is a good example. It examined the effect of PDMPs on physician prescribing behavior using

\footnotetext{
${ }^{4}$ https://www.cdc.gov/phlp/docs/menu-pmcr.pdf contains a description of the scope of various Pill Mill laws across states.

${ }^{5}$ There are other state policies that we do not to include in our analysis (e.g., ID laws and quantity limits). To the extent PDMPs and "pill mill" laws are coincident with these other policies, then estimates of the effect of PDMPs and "pill mill" laws will include the effect of these programs. However, since these laws also are intended to reduce prescription opioid use, the estimates we obtain below on the effects of these state policies on mortality and socioeconomic outcomes still reflect the effect of decrease in prescription opioid use.

${ }^{6}$ We focus on quasi-experimental studies. We do not review other types of studies because of the weak causal analysis frameworks. We describe two of the more comprehensive, observational studies in this note. Brady (2014) conducted a national study of effects of PDMPs on opioid prescriptions from 1999 to 2008 and found no statistically significant effect. However, this study did not differentiate between PDMP types and did not include state fixed effects. Reisman et al. (2009) reported results from a time-series comparison between states that had PDMPs and
} 
data from the National Ambulatory Medical Care Survey from 2001 to 2010 and a difference-indifferences (pre- and post-test with comparison group) research design. This study exploited the significant increase in state PDMPs during this period (see Figure 1). It found that the implementation of a PDMP was associated with a 33\% decline in opioid prescriptions. Dowell et al. (2016) found similar results using a slightly later period of analysis, 2006 to 2013, and data from the IMS National Prescription Audit, which tracks prescriptions dispensed by pharmacies.

Rutkow et al. (2015) conducted a case study of Florida, which adopted a “modern” PDMP and pill mill statute in 2011. The authors examined pre-to-post changes in the prescribing behavior and opioid use of a closed panel (i.e., no compositional change) of physicians, pharmacies and patients. The authors used Georgia as a comparison. Results from the study indicated that opioid prescriptions decreased in Florida by between 2\% and 6\% within 12 months. Two studies of PDMPs used Medicare data and samples of elderly: Moyo et al. (2017) and Buchmueller and Carey (2017). These studies used a difference-indifferences research design and data between 2007 and 2012(or 2013). Buchmueller and Carey reported that must-access PDMPs were associated with modest (2\% to 3\%) reductions in prescription opioid use. Moyo et al. (2017) found that the total quantity (in weight) of opioid prescription declined by approximately 5\%, but that other measures of prescription opioid use did not decrease. An important finding in Buchmueller and Carey (2017) is that it is mainly the required use mandate of a PDMP that causes the decline in opioid use. ${ }^{7}$

The upshot of this brief review is that there is significant evidence that PDMPs have reduced opioid prescriptions. We provide additional evidence of the effectiveness of PDMPs below. From a research point of view, the within-state variation in the creation (extensive margin) and design (intensive margin) of PDMPs, and their apparent effectiveness, facilitates the use of quasi-experimental methods to study the consequences of PDMPs on the use of prescription opioids, mortality, and on socioeconomic outcomes plausibly affected by prescription opioids. This is the overarching objective of this article.

\section{Conceptual Model: Opioid Use versus Opioid Abuse and Implications}

A distinguishing feature of prescription opioid use is that it has both therapeutic and consumption value (euphoria ${ }^{8}$ ). The therapeutic use of prescription opioids is primarily for pain relief, which if untreated can lead to anxiety, depression, functional limitations and increased health care costs (Fishbain

states that did not have PDMPs during the period between 1997 and 2003. PDMPs states experienced slower growth in oxycodone and hydrocodone sales.

${ }^{7}$ Patrick et al. (2016), Birk and Waddell (2017) and Grecu et al. (2019) also emphasize the importance of focusing on specific aspects of PDMPs. All three of these studies reported that PDMPs are associated with fewer serious opioid-related incidents such as treatment admissions and mortality.

${ }^{8}$ We use the term "euphoria" coined by Stigler and Becker (1977) to describe the good associated with use of opioids for pleasure. 
et al. 1986; American Geriatric Association 2002; Bair et al. 2003; Chou et al. 2011). The therapeutic use of prescription opioids is generally health improving, although there is some evidence of inappropriate prescribing that may have limited health benefits ( Kalso et al. 2004; Paplenotiou et al. 2010; Krebs et al.2018). The use of prescription opioids for its consumption (euphoria) value is plausibly health decreasing, particularly if it leads to addiction and heavy use. These fundamentally different uses of prescription opioids need to be incorporated into the conceptual model, particularly given our interest in assessing the effect of changes in prescription opioid use on mortality and socioeconomic outcomes. A second aspect of prescription opioids is that there are close substitutes for its use. Heroin and synthetic opioids, as well as alcohol and other illegal substances, are often used to achieve the same euphoric feeling as non-medical use of prescription opioids. There are also substitutes for the therapeutic use of opioids, such as acetaminophen. Given the availability of close substitutes, changes in use of prescription opioids will cause changes, perhaps large, in the use of these substitutes and dampen the consequences of the changes in opioid use.

In this article, we examine the effect of changes in prescription opioid use brought forth by state prescription opioid control polices, specifically “modern” PDMPs and pill mill statutes. As we show, and others have shown, adoption of PDMPs and pill mill statutes have caused a decrease in prescription opioids. This decrease in prescription opioid use will plausibly affect health and socioeconomic outcomes. However, the effects of a decrease in prescription opioid use on health and socioeconomic outcomes are ambiguous, and depend importantly on the likelihood that the consumer is using prescription opioids for therapeutic purposes, as consumption, or for both therapeutic and consumption purposes.

Consider the person whose only use of prescription opioids is for medical purposes. A policy-induced decrease in prescription opioids for a person who only uses prescription opioids for therapeutic purposes is likely to adversely affect health. This person will have less access to pain relief and less pain relief can have potentially serious effects on health, as noted earlier. In turn, worse health, for example, as manifested in anxiety and depression, can have effects on socioeconomic outcomes, such as labor market outcomes. If, however, the policy-induced decrease in prescription opioids affects primarily opioid use that had relatively low-health benefits, for example, because of moral hazard associated with health insurance, then the adverse health consequences of the policy-induced decrease in opioids may be less substantial. The use of therapeutic substitutes may also lessen the consequences of decreased access to prescription opioids.

Now consider a person whose only use of prescription opioids is for consumption (non-medical) purposes. For this person, a policy-induced decrease in prescription opioids will improve health all else equal. However, all else is not equal because of the availability of close substitutes for non-medical use of 
prescription opioids. The decrease in prescription opioid use that was for consumption (i.e., mis-use) will increase the use of substitutes, such as heroin, alcohol and other illegal drugs, some of which have arguably more serious adverse health effects because of the uncertain quality (adulteration) of these substitutes (e.g., heroin). Therefore, for this person health may improve or worsen. And while the decrease in mis-use of prescription opioids may decrease opioid treatment admissions and prescription opioid use disorder, the increase in use of illegal opioids and other substances will offset these effects. Evidence presented in Grecu et al. (2019) and Evans et al. (2019) is consistent with this argument. Grecu et al. (2019) showed that PDMPs decreased admissions for treatment of opioid use disorder and Evans et al. (2019) reported that decreased access to easy-to-abuse oxycodone increased heroin (fentanyl)-related mortality.

The figures in Table 1 provide some insight into this issue. Table 1 shows means of prescription opioid use, mis-use of prescription opioids, and use of heroin by demographic groups. There are marked differences. Younger people have relatively low rates of prescription opioid use and relatively high rates of mis-use of prescription opioids. Older people have relatively high rates of prescription opioid use and relatively low rates of mis-use of prescription opioids. Men tend to have slightly higher rates of mis-use of prescription opioids than women and women have higher rates of prescription opioid use than men. Surprisingly, there is not a noticeable gradient in prescription opioid use and mis-use by education.

Given the differences in the types of use of prescription opioids by these demographic groups, we may expect a policy-induced decrease in prescription opioids to have different effects across these groups. All else equal, we expect the health of older persons, particularly women, to be adversely affected by the policy change. Of course, if the main effect of the policy was to decrease low-value prescription opioid use and to increase use of substitutes, then health may remain relatively unchanged for these groups. If health does worsen, we may see subsequent changes in socioeconomic outcomes such as employment. On the other hand, the policy-induced decrease in prescription opioids may decrease mis-use of prescription opioids among young persons, particularly men, and increase use of substitutes such as heroin. It is likely, however, that the net effect will be an improvement in health because only a small fraction of young people (men) who misuse prescription opioids use heroin and, while there may be substitution, it is unlikely that it will be sufficient to offset the decrease in mis-use of prescription drugs. ${ }^{9}$ An improvement in health will be likely to have beneficial effects on socioeconomic outcomes, such as employment and earnings. Some evidence that this prediction is likely to hold is presented in Grecu et al. (2019) who

\footnotetext{
${ }^{9}$ Note that mortality may rise, as Evans et al. (2019) find. But mortality is a limited measure of health and is most related to abuse. The conceptual model does not rule this out. We argue that, on average, health will be improved because substitution is likely to be much less than one-for-one.
} 
found that PDMPs reduced admissions for treatment of prescription opioid use, and that there was a strong age gradient in the effect of PDMPs on admissions for treatment.

To summarize, our hypothesis is that a policy-induced decrease in prescription opioids, for example, from states' adoption of PDMPs, may adversely affect health of demographic groups (e.g., older females) that have high rates of medically prescribed opioids. In turn, this decrease in health will adversely affect socioeconomic outcomes. For groups that have high rates of mis-use of prescription opioids, a policy-induced increase in prescription opioids may be health improving and the improvement in health will have subsequent salutary effects. An important caveat to these hypotheses is that they assume that PDMPs have similar effects on prescription opioid use (i.e., the first stage) across demographic groups. This may not be the case. If not, then the predictions described above may not hold. For example, PDMPs may decrease prescription opioid use the most among those who have high rates of medically prescribed opioid use, such as older women. If this is the case, then the predictions noted above are plausible. In contrast, among young men who have high rates of non-medical use of prescription opioids and who presumably obtain prescription opioids through diversion and in the black market, PDMPs may have less effect on their use of prescription opioids. If so, then PDMPs may have little effect on the health and socioeconomic outcomes of this group. The bottom line is that the reduced form effect we estimate consists of the effect of PDMPs on prescription opioid use and the effect of prescription opioid use on outcomes. The demographic differences observed in Table 1 and our hypotheses stemming from those differences focus on the second relationship - the effect of prescription opioids on health and socioeconomic outcomes.

\section{Research Design}

We aim to answer several research questions. First, we obtain estimates of the effect of PDMPs on prescription opioid sales. To accomplish this objective, we use data on retails sales of prescription opioids available from the Drug Enforcement Agency (DEA) of the Department of Justice. The DEA information is from the Automated Reports and Consolidated Ordering System (ARCOS). ${ }^{10}$ We describe these data in detail below, but briefly, the DEA collects and makes publicly available information about the number of quarterly retail sales of prescription opioids at the state level. To these data, we merge information on state PDMPs by state and year.

\section{5.a. Analysis of Prescription Opioid Sales}

Using the ARCOS data at the state and year level, we estimate the following difference-in-difference regression model:

${ }^{10}$ See: https://www.deadiversion.usdoj.gov/arcos/retail_drug_summary/, last accessed May 2, 2019 


$$
\operatorname{OPIOIDS}_{j t}=\alpha_{j}+\delta_{t}+\sum_{k=1}^{3} \beta_{k} \mathrm{PDMP}_{k j t}+\sum_{m=1}^{M} \lambda_{m} A G E_{m j t}+e_{j t}
$$

$$
\text { (1) } \begin{aligned}
j & =1, \ldots, 51 \\
t & =2002, \ldots, 2016
\end{aligned}
$$

In equation (1), the dependent variable is the quantity of retail prescription opioid sales (OPIOIDS) in state $\mathrm{j}$ and year $\mathrm{t}$. The amount of prescription use depends on state fixed effects $\left(\alpha_{\mathrm{j}}\right)$, year fixed effects $\left(\delta_{\mathrm{t}}\right)$, and two policy indicators for whether the state has a "modern" PDMP and a "pill mill” statute. We described the rationale for our classification of state policies earlier and present evidence that the use of “modern” PDMP indicator is a parsimonious approach given the demonstrated effectiveness of various PDMPs. We define the “modern” PDMP and pill mill policies as the proportion of the previous 12 months that the policy was in effect. We do this for each quarterly observation of prescription opioid sales and then we aggregate the quarterly data to the year level. Prescription opioid sales in the state are measured in terms of morphine equivalents grams (MEG), and we use two different measurements: percapita MEG grams and the natural logarithm of per-capita MEG. To construct the per-capita measure, we use the state population. Models also include the share of the state population in 5-year age categories $(A G E)$ as explanatory variables. We include the variables measuring the age distribution in the state to reflect the different rates of usage by age, as shown in Table 1. We also estimate equation (1) using only the combined sales for two of the most frequent opioid prescriptions: oxycodone and hydrocodone.

Our second objective is to obtain estimates of the effects of state policies on mortality and socioeconomic outcomes. Foreshadowing our results, we find that states policies (PDMPs and pill mill statutes) decrease opioid prescription sales significantly. This evidence motivates the analysis of state policies on mortality and socioeconomic outcomes. The outcomes we analyze are death rates, overall and for drug-related deaths, and the following socioeconomic outcomes: employment, weeks worked per year, personal earnings, receipt of social welfare cash benefits, marital status and a measure of disability. The information on mortality comes from vital statistics on deaths collected by the National Center for Health Statistics (NCHS) and for socioeconomic variables we use individual-level data from American Community Surveys (ACS). We describe these data in more detail below.

\section{5.b. Analysis of Mortality and Socioeconomic Outcomes}

For the analyses of mortality and socioeconomic outcomes, we obtain separate estimates for four demographic groups stratified by age (18-34, 35-64) and gender. This stratification is motivated by the evidence in Table 1 that shows significant differences in prescription opioid use and mis-use by these groups. The regression models used to analyze these outcomes are:

(2) $M O R T A L I T Y_{j t}=\tilde{\alpha}_{j}+\tilde{\delta}_{t}+\sum_{k=1}^{3} \tilde{\beta}_{k} P D M P_{k j(t-1)}+u_{j t}$ 
(3) SOCIOECONOMIC $_{i j t}=\breve{\alpha}_{j}+\breve{\delta}_{t}+\sum_{k=1}^{3} \breve{\beta}_{k} P D M P_{k j(t-1)}+\breve{\lambda} D E M O G_{i j t}+v_{i j t}$

There are a couple of differences between equation (1), and equations (2) and (3) that merit mention. First, we do not include the population, or population share, variables in equations (2) and (3). For mortality, which is measured as a rate per 100,000 population, the data are aggregated by age and gender as indicated, and the basic model includes just state and year fixed effects. ${ }^{11}$ We use the same 12-month measure of exposure to the policy measures used in analysis of prescription opioid sales for mortality analysis. For socioeconomic outcomes, we include dummy variable indicators of each year of age, and race/ethnicity (non-Hispanic black, non-Hispanic white, non-Hispanic other, and Hispanic). For analyses of socioeconomic variables, we construct a two-year average measure of exposure to the state opioid policies: for example, in 2012 the policy variables measure the proportion of time that the policy has been in effect in 2011 and 2012. We do this because ACS respondents are interviewed throughout the year from January to December and many of the variables refer to past year values. So, the appropriate measure of exposure for someone interviewed in January 2012 and referring to past year is 2011. For someone interviewed in December 2012, the appropriate exposure measure would be 2012. Because we do not know when a person was interviewed in 2012, we use the average of 2011 and 2012 exposure measures for 2012.

\section{5.c. Threats to Validity}

The difference-in-differences research design represented by equations (1) through (3) is valid under the assumption that, in the absence of the adoption of PDMPs and pill mill statutes, the pre-to-post policy changes in opioid sales, mortality and socioeconomic outcomes would be the same. To bolster and assess the likely validity of this assumption, we do the following. First, we include additional control variables that adjust for potentially different trends in opioid sales, mortality and socioeconomic outcomes that are related to differences in baseline opioid sales. The intuition of this approach is that if states have different baseline levels of opioid sales and other outcomes, then they may have different trends in opioid sales (and in turn mortality and socioeconomic outcomes). Further, if the different level of baseline sales, or different trends, in opioid sales are correlated with states' adoption of policies, adding these controls will adjust for this possibility. Specifically, we construct a set of dummy variables indicating the level of baseline sales of opioids in a state. We created six categories (sextiles). We interact these dummy

\footnotetext{
${ }^{11}$ The NCHS mortality information is not reported for groups with less than 10 deaths per year, and so disaggregating further, for example, by each year of age and including year of age dummy variables in equation (2), would lead to a substantial number of missing cells. To assess whether adding more detailed demographic controls mattered, we re-estimated equation (2) using data disaggregated by year of age and race/ethnicity. We included year of age dummy variables and dummy variables for race/ethnicity. Estimates, which are available from authors, are very similar to those reported in Table 4 . This is not surprising because there is very little variation over time in the age and race/ethnicity distributions with the broader demographic cells used in the analysis of Table 4.
} 
variables with year dummy variables to allow for different year effects for different levels of baseline opioid sales. For analyses of socioeconomic outcomes, we also include interactions between education categories and year and interactions between race categories and year.

Second, we estimate a model that examines whether there are differences in trends in opioid sales, mortality and socioeconomic outcomes in periods prior to the adoption of state policies. This model is sometimes referred to as an "event-study" specification because it tracks the difference in outcomes in periods up to and post the event, which in this case is the adoption of state policies. Evidence of a valid design is that there is no divergence between the trends in outcomes (opioid sales, mortality, socioeconomic outcomes) in periods prior to the adoption of state policies.

\section{5.d. Stratification by Age, Gender and Education}

The conceptual model and figures in Table 1 suggest that the effects of state policies to control prescription opioid use will differ by age and gender, and less so by education. Ideally, we would like to stratify all analyses on these characteristics. However, the ARCOS information on prescription opioid sales does not have information on opioid sales by demographic characteristics. The NCHS and ACS surveys provide demographic characteristics, and for the analyses of the effect of state policies on mortality and socioeconomic outcomes, we obtain estimates for different demographic groups stratified by age and gender, and in some analyses that use the ACS by age, gender and education. Specifically, we divide the sample into four groups using age (18-34, 35-64) and gender. These stratifications are consistent with figures in Table 1 that show different levels of use and mis-use of prescription opioids. In analyses using ACS data, we also stratify by education (high school or less).

\section{Data}

We used several data sources in our analyses. To estimate the effects of state opioid prescription laws on opioid prescribing, we used data on prescription opioid sales from the DEA's Automation of Reports and Consolidated Orders System (ARCOS). We combined these data with information gleaned from the literature on the timing and nature of state prescription opioid policies, which we have previously described. For the analysis of the effect of state policies on mortality, we used data from the National Center for Health Statistics (NCHS) on deaths and causes of death. Again, we combined these data with the information on state opioid policies. To estimate the effect of state policies on socioeconomic outcomes, we used data from the American Community Survey (ACS), which reports individual-level information about demographic characteristics and socioeconomic outcomes. All analyses spanned the period 2002-2016.

\section{6.a. Prescription Opioid Sales}


The Controlled Substance Act of 1970 requires all manufacturers and distributors to report their transactions and deliveries of all Scheduled II-V substances to the Attorney General. The data system to accommodate the Controlled Substance Act reporting requirement is the DEA's Automation of Reports and Consolidated Orders System (ARCOS). ARCOS data are publicly available and we used data from 2002 to 2016. We did not use earlier years because of potential reporting problems. For example, in 2000 only two opioids were reported in ARCOS—Hydrocodone and Oxycodone—and in 2001 California had a huge discrepancy in the total opioid grams reported vis-à-vis 2002.

ARCOS reports total grams of retail prescription opioids sales per quarter per drug (i.e., active ingredient) at the state level. ARCOS reports sales of all schedule II-V substances. We focus on schedule II drugs, which include almost all prescription opioids. In our analysis, we use the top 14 most frequently retailed schedule II opioids (Codeine, Dihydrocodeine, Hydrocodone, Hydromorphone, levorphanol, Meperidine pethidine, Morphine, Oxycodone, Oxymorphone, Opium Powdered, Alfentanil, Remifentanil, Sufentanil base, Tapentadol). ${ }^{12}$ Notably, we exclude Fentanyl, Methadone and Buprenorphine. We exclude these drugs because Methadone and Buprenorphine are prescribed for the management of opioiddependent individuals, and are therefore fundamentally different clinically than the other prescription opioids. We exclude Fentanyl because it is sold primarily in patch and pill form. The Fentanyl patch is more potent than the pill and has a different absorption mechanism. We are unable to distinguish the type of Fentanyl in the ARCOS data and to convert it to a common dosage unit (see below).

There are some limitations of ARCOS. The data over-represent the amounts of prescription opioids that are distributed for human consumption because they include prescriptions used for veterinary purposes. Additionally, these data may over-represent amounts dispensed or consumed by patients because they include amounts re-ordered to replace drugs stolen from pharmacies or other retail-level dispensers, and amounts distributed to the retail level that were not actually dispensed or consumed by patients in the same year.

\section{6.b. Mortality Data}

Mortality data come from the Centers for Disease Control WONDER database, which is based on vital statistics system maintained by the National Center for Health Statistics (NCHS) for years 2002 to 2016. The system provides the overall and cause-specific annual mortality rates (per 100,000) by state and a limited number of demographic characteristics (e.g., age and gender). The sample of analysis contains all U.S. adults ages 18 to 64, which we stratify by age and gender.

\footnotetext{
12 The 14 opioids we selected represent over 99\% of all opioids other than Fentanyl, Methadone and Buprenorphine.
} 
We use two mortality rates: all-cause and drug-related causes, which include ICD-10 codes of X40X44 (drug poisonings, unintentional), X60-X64 (drug poisonings, suicide), X85 (drug poisonings, homicide), and Y10-Y14 (drug poisonings, undetermined intent).

\section{6.c. American Community Survey}

The American Community Survey (ACS) collects information on approximately three million people each year covering over $92 \%$ of the U.S. population. The survey is conducted on a monthly basis throughout the year and combined into an annual file. We limit the sample to adults between the ages of 18 and 64. The ACS collects a wide range of information on individuals and household (age, gender, race, and education). The outcomes we use are: employment at the time of interview, weeks worked in the last year, earnings in the last year, receipt of social assistance income (TANF and SSI), marital status, and disability (cognitive or ambulatory difficulty).

\section{Results}

\section{7.a. Effects of State Policies on Prescription Opioid Sales}

We begin the discussion with results from the event-study specification. The event-study specification is the following:

$$
\text { (4) OPIOIDS }{ }_{j t}=\alpha_{j}+\delta_{t}+\sum_{k=-4}^{4} \beta_{k} M O D E R N_{k j t}+\sum_{k=-4}^{4} \gamma_{k} P I L L M I L L_{k j t}+\sum_{m=1}^{M} \lambda_{m} A G E_{m j t}+e_{j t}
$$

In equation (4), we allow the effect of adopting a modern PDMP and a pill mill statute to differ by the timing of the policy. We estimate equation (4) using the extended model that adds baseline opioid sales interacted with year effects. We estimate this model for both per-capita MEG and log per-capita MEG, and for all prescription opioids and only hydrocodone and oxycodone prescriptions.

The results of the event-study specification are presented in Figures 2 and 3. Figure 2 shows results related to the "modern” PDMP policy. There are four graphs showing estimates for all opioid sales (Panel A) and estimates for hydrocodone and oxycodone (Panel B). Within each panel there are two graphs showing estimates for log per-capita sales and per-capita sales. There is much consistency across estimates shown in Figure 2. In the period prior to the adoption of a "modern” PDM opioid sales show no differential trend between states that did and did not adopt this type of PDMP. Subsequent to the adoption of a "modern" PDMP, opioid sales decline in states that adopt the law relative to states that do not. The decline is approximately $5 \%$ to $7 \%$ for log per-capita grams and $12 \%$ to $20 \%$ for per-capita grams.

Figure 3 shows analogous estimates for pill mill statutes. The pattern of estimates is similar to that just described. Prior to adoption of a pill mill law, there were no differential trends in opioid sales between states that did and did not adopt such a law. Subsequent to adoption, opioid sales in states that adopted a pill mill law decreased relative to opioid sales in states that did not adopt a law. The declines 
are substantial and statistically significant: approximately $20 \%$ for log per-capita grams and $40 \%$ for percapita grams.

The next set of estimates are from a standard difference-in-differences model that examines the pre-to-post policy adoption changes in opioid sales combining pre- and post-adoption years into two separate periods. Estimates are presented in Table 2. The top panel of Table 2 reports estimates for all opioid sales and the bottom panel reports estimates for oxycodone and hydrocodone. The left panel of Table 2 reports estimates for opioid sales measured as per-capita MEG and the right panel reports estimates for opioid sales measured as the logarithm of per-capita MEG. In each of the four panels, we report estimates for two model specifications: a basic model that includes state and year fixed effects, and controls for the age distribution of the state; and a second model that adds interactions between baseline opioid sales and year effects.

Estimates in the top panel indicate that implementation of a "modern" PDMP is associated with approximately a 10\% (0.04 unit) decline in per-capita opioid sales and approximately a $4 \%$ decline in prescription opioid sales when per-capita sales are measured in log form. For pill mill laws, estimates indicate that implementation of such a statute is associated with approximately a $28 \%$ (0.11 unit) decrease in per-capita prescription opioid sales and 15\% decrease in per-capita sales when measured in log form. All estimates are statistically significant. The difference in effect sizes by whether the dependent variable is measured in absolute or log form is likely due to the very different levels of per-capita prescription opioids across states. In 2002, the mean per-capita prescription opioid sales was 0.39 with a minimum of 0.25 and a maximum of 0.75 . Estimates from models that use log per-capita sales gives more weight to small increases in states with low levels of per-capita sales. Estimates are quite stable across the two model specifications, which is consistent with earlier results from the event-study analysis and supportive evidence of a valid research design.

The bottom panel of Table 2 presents estimates related to the top two opioid prescriptions: hydrocodone and oxycodone. Estimates for this measure of prescription opioids are larger than they were for all opioid prescriptions and always statistically significant. With respect to implementation of a “modern” PDMP, estimates indicate that this policy is associated with approximately a 16\% (0.04 unit) decrease in per-capita sales of these opioids and a 7\% decrease when measured in log per-capita sales. Pill mill laws are associated with a 44\% (0.11 unit) decrease in per-capita sales of hydrocodone and oxycodone and approximately a $23 \%$ decrease when measured in log per-capita form. Again, estimates are stable across the two model specifications. The fact that the coefficients on the two state policies are approximately the same when either all opioid sales or just sales of hydrocodone and oxycodone are used as the dependent variable suggests that these policies mainly affected sales of hydrocodone and oxycodone. 
We also assessed whether it was appropriate to use a more detailed classification of PDMP policies. Appendix Table 1 reports estimates analogous to those in Table 2, but with an expanded classification of PDMP policies. In this analysis, we use three, mutually exclusive indicators to classify PDMPs: whether a state had a PDMP that was electronic; whether the PDMP was "modern”; and whether it was "modern” and had a mandate to use. Results from these models suggest that our more parsimonious specification is empirically valid and estimates of the effect of a "modern” PDMP and pill mill are quite similar in the extended and more parsimonious models.

Overall, evidence presented in Figures 2 and 3, and Table 2, suggest that state policies have significantly reduced opioid sales. This finding is similar to some previous studies (Bao et al. 2016; Dowell et al. 2016; Buchmueller and Carey 2017; Moyo et al. 2017). Effect sizes are non-trivial and particularly large for pill mill statutes, and larger and more significant reductions in response to these laws was found for hydrocodone and oxycodone, which are the top two prescription opioids.

In the next section, we examine how these policies affect mortality and socioeconomic outcomes. We note that our analysis of the effect of PDMPs and pill mill laws on opioid sales was at an aggregate level. We were unable to identify whether these laws had different effects on different demographic groups, which may be expected by the evidence in Table 1 related to differences in medical and mis-use of prescription opioids. Therefore, the aggregate effects presented above may mask substantial heterogeneity of the effects of these policies on prescription opioid use across demographic groups.

\section{7.b. Effects of State Policies on Mortality}

Table 3 presents estimates of the effects of the two state polices on all-cause mortality for four demographic groups stratified by age and gender. For each group, two model specifications are presented: a basic model (state and year fixed effects) and a model that also includes baseline opioids by year interactions. We focus our discussion on the results from the second model, but note that estimates are quite similar across specifications.

Estimates of the effect of a "modern" PDMP on all-cause mortality are negative, small relative to the mean and not statistically significant. The largest estimates are for young males and females. For these samples, adoption of a "modern” PDMP is associated with a $2 \%$ decrease in all-cause mortality. For pill mill laws, estimates are mixed. Among persons ages 35 to 64, pill mill laws are associated with an increase in all-cause mortality and the estimate for females is $4 \%$ (13.2) and marginally significant. Among younger persons, pill mill laws are associated with a decline in all-cause mortality of $2 \%$ (females) to 4\% (males), but not statistically significant. One issue related to the mortality estimates is whether there is sufficient statistical power to detect a population level effect. Consider pill mill laws, which were associated with a substantial decline in opioid sales of between $15 \%$ to $44 \%$ depending on 
what dependent variable was used (e.g., log or level of per-capita sales). For illustrative purpose, assume the effect is $25 \%$, that $20 \%$ of the population is likely affected, and that the reduction in opioid sales was a result of a smaller fraction of the population using opioids. This implies that $5 \%$ less of the population used prescription opioids. If the decrease in opioid use was associated with a $20 \%$ reduction in all-cause mortality, then we expect all-cause mortality to decline by $1 \%$. In most case, we do not have sufficient statistical power to detect reliably an effect size of this magnitude. This will not be the case for drugrelated mortality, which we discuss below.

Before moving on to the results related to drug-related mortality, we report on the results from eventstudy analysis of all-cause mortality. In Appendix Figures 1 and 2, we present estimates from the eventstudy specification analogous to the regression models used in Table 3 for the four demographic groups stratified by age and gender. Estimates in these figures show no evidence of an invalid research design. Prior to adoption of state policies, there was no noticeable or significant deviation in the trend in all-cause mortality.

Table 4 reports estimates of the effect of state polices on drug-related mortality. Again, we focus on estimates form the expanded regression model specification that includes interactions between baseline opioid use and year dummy variables. Estimates are qualitatively similar across the two specifications, but there are some noticeable differences in the magnitudes. ${ }^{13}$ The causes of mortality included in this analysis are listed in the notes to the table and are several types of drug poisonings. In this case, there is little evidence of a statistically significant effect of a “modern” PDMP or pill mill law on drug-related mortality. Estimates for both policies are almost always negative, but not significant. Effect sizes are relatively small $(<5 \%)$ for the older sample of persons ages 35 to 64. However, among those ages 18 to 34 , effect sizes are substantial. Adoption of a “modern” PDMP is associated with a $14 \%$ decrease in drugrelated mortality for females and a 7\% decrease in drug-related mortality for males. Among young males (ages 18 to 34), pill mill laws are associated with a $21 \%$ (4.5 per 100,000) decrease in drug-related mortality.

The effect size of the pill mill estimate for young males is plausible. Approximately $10 \%$ of men of this age mis-use prescription opioids (self-reported). If 20\% of these men stopped mis-using prescription opioids because of a pill mill law, then we would expect a similar decrease in drug-related mortality because it is this group of men that are dying from drug-related causes (those who do not use drugs cannot die from a drug-related cause). A 20\% decline in drug-related causes implies a decrease of 4.3 deaths per 100,000 for men ages 18 to 34. Estimates of the effect of pill mill laws in Table 4 are approximately 4.5 deaths per 100,000. The standard error of the estimate of the effect of pill mill laws for

\footnotetext{
${ }^{13}$ Appendix Figures 3 and 4 present the event-study estimates. These figures provide evidence that supports the validity of the difference-in-differences research design.
} 
this group is 3.6, a bit too large to detect reliably an effect size of this magnitude. While these calculations are approximate, they indicate that the analysis is adequately powered to detect moderate effect sizes. In addition, the pattern of results is consistent with the conceptual model described earlier. Young persons, particularly men, have relatively high rates of mis-use of prescription opioids and the decrease in opioid sales (use) caused by adoption of a “modern” PDMP or pill mill laws are expected to reduce this mis-use and the consequences of that mis-use. The mortality declines for the younger sample, particularly men, suggested by the estimates in Table 4 are consistent with this prediction, but we note, again, estimates are not statistically significant.

Our findings that a “modern” PDMP and pill mill laws have, generally, small to no significant effect on mortality are consistent with some prior studies, although the literature remains relatively sparse. We also note that our analysis, and other similar analyses, are under powered to detect reliably small effect sizes expected for all-cause mortality. Grecu et al (2019) reported that PDMPs were associated with a $25 \%$ decline in opioid-related mortality among persons ages 18 to 24 ; we found a smaller effect (7\% to 14\%) for persons ages 18 to 34. Grecu et al. (2019) reported no significant change in all-cause mortality for those ages 18 to 24 and no effects of PDMPs on mortality for other groups. Paulozzi et al. (2011) compared state level opioid sales (ARCOS) and mortality in PDMP and non-PDMP states between 1999 and 2005 and found that PDMPs were not associated with declines in either opioid sales or morality. Similarly, Li (2014) compared states with and without PDMPs from 1999 to 2008 and found no difference in drug overdose mortality.

\section{7.c. Effects of State Policies on Socioeconomic Outcomes}

Prescription opioid use and mis-use may affect socioeconomic outcomes because of the effects of prescription opioids on health (e.g., pain relief) and through consumption pathways, for example, mis-use and the adverse consequences of such use. We have shown that state prescription opioid control policies decreased opioid sales substantially and presumably opioid use too. Therefore, it is plausible that state policies have affected socioeconomic outcomes, such as employment and earnings. We present evidence on this issue next.

Table 5 presents estimates of the effects of state policies on the probability of being employed at the time of survey. The table shows results for several demographic groups and for two model specifications in different panels (top and bottom). We focus the discussion on results in the bottom panel, but note that estimates are similar across the two panels. ${ }^{14}$ Estimates indicate that the adoption of a

\footnotetext{
${ }^{14}$ Appendix figures 5 and 6 show the event-study estimates. While generally supportive of the research approach, among those ages 18 to 34 there is some divergence in trends in employment prior to adoption of a "modern" PDMP; this is not the case for pill mill laws.
} 
"modern” PDMP is associated with a significant decrease in the probability of being employed for all demographic groups. Estimates are a bit larger for those ages 18 to 34 than for the older sample and somewhat larger for males than females. However, estimates are a small. For example, adoption of a “modern” PDMP is associated with a $1 \%$ to $1.5 \%$ decrease in the probability of being employed for those ages 18 to 34. Estimates in Table 5 pertaining to pill mill laws are small and mostly positive, but not statistically significant.

We note that standard errors of estimates in Table 5 are small enough to detect reliably effect sizes that are very small. This information is important because estimates in Table 5 are population estimates, but as previously noted, only a fraction of the population — those who use prescription opioids — is likely affected by the state policies. If we assume that $15 \%$ of the sample uses prescription opioids and state policies decrease that use by $20 \%$, then the percent of the population affected is $3 \%$ (3 percentage points of the population). Standard errors in Table 5 can detect reliably an effect size of approximately 0.5 percentage points — or $1 / 6^{\text {th }}$ the size of the decline in prescription opioid use in the population. Of course, this calculation is a rough approximation, but it shows that we can detect reliably small effects at the population level that are consistent with small to moderate effects $\left(1 / 6^{\text {th }}\right.$ or $\left.17 \%\right)$ at the individual level (i.e., treatment on the treated).

Appendix Table 2 presents estimates of the effect of a "modern” PDMP and pill mill law on the probability of being employed among a sample of persons with a high school degree or less. While the figures in Table 1 did not suggest a strong gradient in prescription opioid use by education, which is surprising, there remains the possibility that the state opioid control policies would have different effects on prescription opioid use by education and prescription opioid use would have different effects on employment. As estimates in Appendix Table 2 reveal, however, effect of the state policies on employment is similar for the low-educated samples, although effects are larger (e.g., $2 \%$ instead of $1 \%$ ).

In Table 6 we present estimates of the effect of a "modern” PDMP and pill mill law on a different measure of labor supply_probability of working 48 or more weeks (full year) in the past year. Much of the description of results provided with respect to Table 5 apply here. Estimates indicate that the adoption of a “modern” PDMP is associated with a small (e.g., 1\%), but (marginally) significant decrease in the probability of being employed full-year for all demographic groups. Estimates pertaining to pill mill laws are all positive and small, although among those ages 18 to 35, estimated effect sizes are $2 \%$ and significant for females. Estimates for a low-educated sample (Appendix Table 3) are similar.

The next outcome we examined was earned income in the past 12 months, which is measured in thousands of 2010 dollars and includes people with zero earnings. Estimates of the effects of state policies on this outcome are shown in Table 7. It is again the case that estimates across the two model specifications are very similar and we focus the discussion on those in the bottom. Only one estimate in 
the bottom panel is statistically significant and only marginally so. However, there is one pattern among the estimates that is readily identifiable: adoption of a "modern” PDMP is always associated with a decrease in earned income and the adoption of a pill mil statute is almost always associated with an increase in earned income. This pattern is more pronounced (e.g., larger relative effects) among younger cohorts than older cohorts and among males than females. For example, adoption of a "modern” PDMP is associated with between a $\$ 576$ (3\% of a standard deviation) decrease in earned income among males ages 18 to 34. Adoption of a pill mill law has the opposite effect for this demographic group: an increase in earnings of \$995 (5\%). These opposite effects of a “modern” PDMP and pill mill law on earnings is consistent with the effects of these policies on employment: a "modern” PDMP was associated with a decrease in employment and a pill mill law was associated with an increase in employment. The pattern of results just described is even more pronounced among a sample of low-educated persons (see Appendix Table 4). In this sample, all of the estimates associated with a “modern” PDMP are statistically significant. Estimates related to both policies are also larger.

We next present results of the effect of state opioid policies on receipt of cash social assistance: TANF or SSI. ${ }^{15}$ Estimates are in Table 8 and estimates in the top and panel panels are virtually same. The mean of the dependent variable is quite small (3\% to 6\%) for this outcome and estimates reflect this and are also small in absolute size. Nevertheless, estimates indicate that a "modern” PDMP is associated with an increase in the probability of receiving pubic cash assistance and estimates for females are statistically significant. Among women, adoption of a "modern” PDMP is associated with a $1 \%$ to $3 \%$ increase in receipt of public cash assistance. These estimates align with analogous estimates related to employment and earnings. Adoption of a pill mill law is associated with a 0.2 percentage point (3\%) increase in receipt of cash assistance. While this is a statistically significant, it does not align with other estimates, for example, related to labor market. Estimates for a low-educated sample are presented in Appendix Table 5 and are very similar to those just described.

Table 9 presents estimates of the effect of state policies on the probability of being married and living with a spouse. Both of the opioid control policies are associated with a decrease in the probability of being married for persons ages 18 to 34, and for women ages 35 to 64 . In relative terms, the effect of state opioid control policies is larger for those ages 18 to 34: approximately $1 \%$ to $2 \%$ decline in probability of being married. Estimates for the low-educated sample (Appendix Table 6) are quite similar.

The last set of results is from an analysis of the effect of PDMPs and pill mill laws on the probability of having a cognitive or ambulatory problem, for example, difficulty learning or making

\footnotetext{
${ }^{15}$ We do not examine Medicaid, which may be a likely consequence of opioid use, because prior to 2008, the ACS does not include such information.
} 
decisions because of a physical, mental or emotional condition, or difficulty with basic physical activities. Estimates in Table 10 (Appendix Table 7) are all insignificant and small, and there are few noticeable patterns that would suggest an effect of PDMPs or pill mill laws on these health-related problems.

\section{Conclusion}

The opioid "epidemic" is a major public health problem, primarily because of the adverse consequences opioid mis-use (abuse) has on mortality. While the mortality consequences of prescription opioid use garner the most public attention, and rightfully so given the value of life, prescription opioid use may affect other aspects of life that determine wellbeing, such as employment, earnings and marriage. There has been little study of this issue. In this article, we provide evidence on this research question. We also incorporate the fact that most prescription opioid use is medically prescribed and arguably clinically indicated, and that the effect of reductions in prescription opioids may have different effects depending on whether prescription opioid use is medically prescribed or mis-used. We identify demographic groups that have very different profiles of prescription opioid use in terms of whether it is mis-use or medically prescribed use, and we examine these groups separately.

A key feature of our research was that we exploited changes in prescription opioid use that was plausibly exogenous and a result of state policies. States have undertaken a variety of policies to stem opioid use, particularly prescription opioid use. The most prominent policies are PDMPs and "pill mill” statutes. In this article, we showed that adoption of PDMP that is what we refer to as "modern" decreased all opioid prescription sales by between $5 \%$ to $10 \%$ and decreased sales of the top two prescriptions (hydrocodone and oxycodone) by between $7 \%$ and $20 \%$. Pill mill statutes had even larger effects decreasing all opioid prescription sales by between $14 \%$ and $28 \%$ and decreased hydrocodone and oxycodone prescriptions by $20 \%$ to $48 \%$. These reductions in opioid sales, and presumably opioid use, motivated our analysis of the effect of state policies on mortality and socioeconomic outcomes.

Results suggest that the reductions in opioid prescriptions associated with a "modern” PDMP and pill mill laws had relatively little statistically significant effects on mortality. However, adoption of a “modern” PDMP was associated with a 14\% decrease in drug-related mortality for females and a 7\% decrease in drug-related mortality for males. Among young males (ages 18 to 34), pill mill laws are associated with a $21 \%$ (4.5 per 100,000) decrease in drug-related mortality. However, estimates were not statistically significant.

In terms of socioeconomic outcomes, we found consistent evidence that a "modern" PDMP was associated with a small (e.g., 2\%) decrease in employment and earnings, and an increase in receipt of public assistance. In contrast, pill mill laws were associated with a small increase in employment and earnings. These associations just described were larger for a low-educated sample. In the case of 
marriage, both state policies were associated with a decrease in the probability of married, particularly for those ages 18 to 34 and for women ages 35 to 64. Effect sizes were also small (2\%).

In terms of population wellbeing, a "modern” PDMPs and pill mill law were associated with small changes and, surprisingly, with opposite signed effects. As just noted, adoption of a “modern” PDMP was associated with less employment and earnings and a pill mill law was associated with greater employment and higher earnings, although effects were quite small. Our speculation is that these opposite signed effects reflect the different effects of these policies on use and mis-use of prescription opioids. The pattern of effects suggests that the decline in prescription opioid use associated with pill mill laws caused a reduction in mis-use that resulted in improvements in wellbeing while the decline in prescription opioid use caused by adoption of a "modern" PDMP was for therapeutic purposes and resulted in a decrease in wellbeing. Future research is needed to assess whether our speculation is correct.

We note that the proportion of the population that mis-uses prescription opioids is relatively small and the proportion with a prescription opioid abuse disorder is even smaller-less than $1 \%$ of the population (McCance-Katz 2018). Therefore, the likely reduction in prescription opioid mis-use brought forth by state policies will have small although potentially important effects, for example, a decrease in mortality (although some evidence on mortality is inconsistent with hypothesis). Our results related to pill mill laws is consistent with this hypothesis. In contrast, a relatively large share of the population uses medically prescribed prescription opioids and limits their use to medical purposes. Reductions in medically prescribed opioids may not have all positive benefits. Indeed, there has been a growing concern that the pendulum has swung too far and that appropriate prescription opioid use is being curtailed (Dowell et al. 2019; Bohnert et al. 2019; Kroenke et al. 2018). If so, then curtailing such prescription use through PDMPs and "pill mill” laws will affect a relatively large share of the population and may have adverse consequences on wellbeing. Our results related to adoption of a "modern” PDMP supports this hypothesis. 


\section{References}

American Geriatrics Society (AGS) Panel on Persistent Pain in Older Adults. 2002. The management of persistent pain in older persons. www.americangeriatrics.org/products/positionpapers/JGS5071.pdf.

Bair MJ, Robinson RL, Katon W, Kroenke K. Depression and Pain Comorbidity: A Literature Review. Arch Intern Med. 2003;163(20):2433-2445. doi:10.1001/archinte.163.20.2433

Bao, Y., Pan, Y., Taylor, A., Radakrishnan, S., Luo, F., Pincus, H.A. and Schackman, B.R., 2016. Prescription drug monitoring programs are associated with sustained reductions in opioid prescribing by physicians. Health Affairs, 35(6), pp.1045-1051.

Birk, Erica and Waddell, Glen R., The Mitigating Role of Prescription Drug Monitoring Programs in the Abuse of Prescription Drugs. IZA Discussion Paper No. 10990. Available at SSRN: https://ssrn.com/abstract=3037875

Bohnert, A.S., Guy, G.P. and Losby, J.L., 2018. Opioid prescribing in the United States before and after the Centers for Disease Control and Prevention's 2016 opioid guideline. Annals of internal medicine, 169(6), pp.367-375.

Brady, J.E., Wunsch, H., DiMaggio, C., Lang, B.H., Giglio, J. and Li, G., 2014. Prescription drug monitoring and dispensing of prescription opioids. Public Health Reports, 129(2), pp.139-147.

Buchmueller, T.C. and Carey, C., 2018. The effect of prescription drug monitoring programs on opioid utilization in medicare. American Economic Journal: Economic Policy, 10(1), pp.77-112.

Centers for Disease Control and Prevention. "annual surveillance report of drug-related risks and outcomes_United States. Surveillance Special Report. August 31, 2018." (2019). Accessed April, 2010 from https://www.cdc.gov/drugoverdose/pdf/pubs/2019-cdc-drug-surveillance-report.pdf

Centers for Disease Control and Prevention. "US opioid prescribing rate maps." CDC. Last modified October 3 (2018). Accessed April, 2010 from https://www.cdc.gov/drugoverdose/maps/rxratemaps.html

Chou, R., Fanciullo, G.J., Fine, P.G., Adler, J.A., Ballantyne, J.C., Davies, P., Donovan, M.I., Fishbain, D.A., Foley, K.M., Fudin, J. and Gilson, A.M., 2009. Clinical guidelines for the use of chronic opioid therapy in chronic noncancer pain. The Journal of Pain, 10(2), pp.113-130.

Currie, J., Jin, J.Y. and Schnell, M., 2018. US employment and opioids: Is there a connection? (No. w24440). National Bureau of Economic Research.

Dowell, D., Haegerich, T. and Chou, R., 2019. No shortcuts to safer opioid prescribing. New England Journal of Medicine.

Dueñas, M., Ojeda, B., Salazar, A., Mico, J.A. and Failde, I., 2016. A review of chronic pain impact on patients, their social environment and the health care system. Journal of pain research, 9, p.457.

Finley, E.P., Garcia, A., Rosen, K., McGeary, D., Pugh, M.J. and Potter, J.S., 2017. Evaluating the impact of prescription drug monitoring program implementation: a scoping review. BMC health services research, 17(1), p.420. 
Fishbain, D.A., Goldberg, M., Meagher, B.R., Steele, R. and Rosomoff, H., 1986. Male and female chronic pain patients categorized by DSM-III psychiatric diagnostic criteria. Pain, 26(2), pp.181-197.

Fulton-Kehoe, D., Garg, R.K., Turner, J.A., Bauer, A.M., Sullivan, M.D., Wickizer, T.M. and Franklin, G.M., 2013. Opioid poisonings and opioid adverse effects in workers in Washington State. American journal of industrial medicine, 56(12), pp.1452-1462.

Gau, J.M., Moreto, W.D., Potter, R.H., Brooke, E.J., University of Central Florida and United States of America, 2017. Non-medical Use of Prescription Drugs: Policy Change, Law Enforcement Activity, and Diversion Tactics. Department of Criminal Justice, University of Central Florida.

Grecu, A.M., Dave, D.M. and Saffer, H., 2019. Mandatory access prescription drug monitoring programs and prescription drug abuse. Journal of Policy Analysis and Management, 38(1), pp.181-209.

Gustavsson, A., Bjorkman, J., Ljungcrantz, C., Rhodin, A., Rivano-Fischer, M., Sjolund, K.F. and Mannheimer, C., 2012. Socio-economic burden of patients with a diagnosis related to chronic painRegister data of 840,000 Swedish patients. European journal of pain, 16(2), pp.289-299.

Harris, M.C., Kessler, L.M., Murray, M.N. and Glenn, B., 2019. Prescription Opioids and Labor Market Pains: The Effect of Schedule II Opioids on Labor Force Participation and Unemployment. Journal of Human Resources, pp.1017-9093R2.

Horwitz, J., Davis, C.S., McClelland, L.S., Fordon, R.S. and Meara, E., 2018. The problem of data quality in analyses of opioid regulation: The case of prescription drug monitoring programs (No. w24947). National Bureau of Economic Research.

International Narcotics Control Board, 2006. Narcotic Drugs: Estimated World Requirements for..., Statistics for.. (No. 1-3). United Nations Public

Kenan, K., Mack, K. and Paulozzi, L., 2012. Trends in prescriptions for oxycodone and other commonly used opioids in the United States, 2000-2010. Open Medicine, 6(2), p.e41.

Kroenke, K., Alford, D.P., Argoff, C., Canlas, B., Covington, E., Frank, J.W., Haake, K.J., Hanling, S., Hooten, W.M., Kertesz, S.G. and Kravitz, R.L., 2019. Challenges with Implementing the Centers for Disease Control and Prevention Opioid Guideline: A Consensus Panel Report. Pain Medicine.

Krueger, A.B., 2017. Where have all the workers gone? An inquiry into the decline of the US labor force participation rate. Brookings papers on economic activity, 2017(2), p.1.

Li, G., Brady, J.E., Lang, B.H., Giglio, J., Wunsch, H. and DiMaggio, C., 2014. Prescription drug monitoring and drug overdose mortality. Injury epidemiology, 1(1), p.9.

Mallatt, J., 2017. The effect of prescription drug monitoring programs on opioid prescriptions and heroin crime rates. Available at SSRN 3050692.

Manchikanti, L., Kaye, A.M., Knezevic, N.N., McAnally, H., Trescot, A.M., Blank, S., Pampati, V., Abdi, S., Grider, J.S., Kaye, A.D. and Manchikanti, K.N., 2017. Responsible, safe, and effective prescription of opioids for chronic non-cancer pain: American Society of Interventional Pain Physicians (ASIPP) guidelines. Pain Physician, 20(2), pp.S3-S92. 
Manchikanti, L., Brown, K.R. and Singh, V., 2002. National All Schedules Prescription Electronic Reporting Act (NASPER): balancing substance abuse and medical necessity. Pain Physician, 5(3), pp.294-319.

McCance-Katz, Elinore. 2018. “An Update on the Opioid Crisis. https://www.samhsa.gov/sites/default/files/aatod 2018 final.pdf, website last accessed May 14, 2019

Moyo, P., Simoni-Wastila, L., Griffin, B.A., Onukwugha, E., Harrington, D., Alexander, G.C. and Palumbo, F., 2017. Impact of prescription drug monitoring programs (PDMPs) on opioid utilization among Medicare beneficiaries in 10 US States. Addiction, 112(10), pp.1784-1796.

Paulozzi, L.J., Weisler, R.H. and Patkar, A.A., 2011. A national epidemic of unintentional prescription opioid overdose deaths how physicians can help control it. The Journal of clinical psychiatry.

Patrick, S.W., Fry, C.E., Jones, T.F. and Buntin, M.B., 2016. Implementation of prescription drug monitoring programs associated with reductions in opioid-related death rates. Health Affairs, 35(7), pp.1324-1332.

Patrick, S.W., Fry, C.E., Jones, T.F. and Buntin, M.B., 2016. Implementation of prescription drug monitoring programs associated with reductions in opioid-related death rates. Health Affairs, 35(7), pp.1324-1332.

Ratcliffe, M., Burd, C., Holder, K. and Fields, A., 2016. Defining rural at the US Census Bureau. American community survey and geography brief, pp.1-8.

Reisman, R.M., Shenoy, P.J., Atherly, A.J. and Flowers, C.R., 2009. Prescription opioid usage and abuse relationships: an evaluation of state prescription drug monitoring program efficacy. Substance abuse: research and treatment, 3, pp.SART-S2345.

Rutkow, L., Turner, L., Lucas, E., Hwang, C. and Alexander, G.C., 2015. Most primary care physicians are aware of prescription drug monitoring programs, but many find the data difficult to access. Health Affairs, 34(3), pp.484-492.

Tao, X.G., Lavin, R.A., Yuspeh, L. and Bernacki, E.J., 2012. Impact of the combined use of opioids and surgical procedures on workers' compensation cost among a cohort of injured workers in the state of Louisiana. Journal of occupational and environmental medicine, 54(12), pp.1513-1519.

Turk, D.C., Fillingim, R.B., Ohrbach, R. and Patel, K.V., 2016. Assessment of psychosocial and functional impact of chronic pain. The Journal of Pain, 17(9), pp.T21-T49.

Weiner, S.G., Baker, O., Rodgers, A.F., Garner, C., Nelson, L.S., Kreiner, P.W. and Schuur, J.D., 2017. Opioid prescriptions by specialty in Ohio, 2010-2014. Pain Medicine, 19(5), pp.978-989. 
Table 1 - Mean Drug Use by Age, Education and Gender, 2002-2006

\begin{tabular}{|c|c|c|c|c|c|c|c|c|}
\hline & \multicolumn{2}{|c|}{$\begin{array}{c}\text { Females } \\
\text { Age 18-34 }\end{array}$} & \multicolumn{2}{|c|}{$\begin{array}{c}\text { Females } \\
\text { Age 35-64 }\end{array}$} & \multicolumn{2}{|c|}{$\begin{array}{c}\text { Males } \\
\text { Age 18-34 }\end{array}$} & \multicolumn{2}{|c|}{$\begin{array}{c}\text { Males } \\
\text { Age 35-64 }\end{array}$} \\
\hline & $\begin{array}{c}\leq \mathrm{HS} \\
\text { Education }\end{array}$ & $\begin{array}{c}>\text { HS } \\
\text { Education }\end{array}$ & $\begin{array}{c}\leq \mathrm{HS} \\
\text { Education }\end{array}$ & $\begin{array}{c}>\text { HS } \\
\text { Education }\end{array}$ & $\begin{array}{c}\leq \mathrm{HS} \\
\text { Education }\end{array}$ & $\begin{array}{c}>\text { HS } \\
\text { Education }\end{array}$ & $\begin{array}{c}\leq \mathrm{HS} \\
\text { Education }\end{array}$ & $\begin{array}{c}>\text { HS } \\
\text { Education }\end{array}$ \\
\hline $\begin{array}{l}\text { Any Non-medical Use } \\
\text { Pain Reliever Past Year }\end{array}$ & 0.099 & 0.083 & 0.029 & 0.025 & 0.100 & 0.108 & 0.029 & 0.026 \\
\hline $\begin{array}{l}\text { Any Medical Use Pain } \\
\text { Reliever Past Year }\end{array}$ & 0.137 & 0.121 & 0.163 & 0.146 & 0.073 & 0.075 & 0.129 & 0.113 \\
\hline Any Heroin Use Past Year & 0.004 & 0.002 & 0.001 & 0.0003 & 0.004 & 0.004 & 0.001 & 0.0003 \\
\hline $\begin{array}{l}\text { Heroin or Non-medical } \\
\text { Pain Reliever Past Year }\end{array}$ & 0.100 & 0.085 & 0.029 & 0.025 & 0.101 & 0.108 & 0.029 & 0.026 \\
\hline $\begin{array}{l}\text { Any Illicit Drug Not } \\
\text { Marijuana Past Year }\end{array}$ & 0.168 & 0.145 & 0.050 & 0.046 & 0.161 & 0.188 & 0.050 & 0.047 \\
\hline
\end{tabular}

Notes - All means except medical use of pain relievers are estimated using data from the 2002 to 2006 National Survey on Drug Use and Health. Non-Medical use of pain reliever is defined as the use of these drugs without a prescription or use that occurs simply for the experience or feeling the drug causes; use of over-the-counter (OTC) drugs and legitimate use of prescription-type drugs are not included in the non-medical use definition. Mean medical use of pain relievers is from the Medical Expenditure Survey from 2002 to 2006. Medical use of pain relievers is defined as those drugs which are ordered by a physician or other authorized medical personnel. 
Table 2. Estimates of the Effects of State Policies on Retail Opioid Prescriptions, 2002-2016

\begin{tabular}{|c|c|c|c|c|}
\hline \multirow{2}{*}{$\frac{\text { All Opioids }}{\text { Modern }}$} & \multicolumn{2}{|c|}{ Per-capita MEG Grams } & \multicolumn{2}{|c|}{ Log Per Capita MEG Grams } \\
\hline & $\begin{array}{c}-0.043 \\
(0.032)\end{array}$ & $\begin{array}{c}-0.040 \\
(0.030)\end{array}$ & $\begin{array}{c}-0.043 \\
(0.033)\end{array}$ & $\begin{array}{l}-0.049 \\
(0.032)\end{array}$ \\
\hline Pill Mill & $\begin{array}{c}-0.105^{* *} \\
(0.039)\end{array}$ & $\begin{array}{c}-0.124^{* *} \\
(0.030)\end{array}$ & $\begin{array}{c}-0.142 * * \\
(0.038)\end{array}$ & $\begin{array}{c}-0.158 * * \\
(0.036)\end{array}$ \\
\hline P-value of F-Test of Joint Significance & 0.029 & 0.000 & 0.001 & 0.000 \\
\hline $\begin{array}{l}\text { Mean of Dependent Variable in } 2002 \\
\text { Hydrocodone/Oxycodone }\end{array}$ & 0.39 & 0.39 & & \\
\hline Modern & $\begin{array}{l}-0.050 * \\
(0.027)\end{array}$ & $\begin{array}{c}-0.036^{*} \\
(0.018)\end{array}$ & $\begin{array}{c}-0.079 * * \\
(0.030)\end{array}$ & $\begin{array}{c}-0.072 * * \\
(0.026)\end{array}$ \\
\hline Pill Mill & $\begin{array}{c}-0.113^{* *} \\
(0.042)\end{array}$ & $\begin{array}{c}-0.122^{* *} \\
(0.036)\end{array}$ & $\begin{array}{c}-0.260 * * \\
(0.056)\end{array}$ & $\begin{array}{c}-0.202^{* *} \\
(0.056)\end{array}$ \\
\hline P-value of F-Test of Joint Significance & 0.030 & 0.002 & 0.000 & 0.000 \\
\hline Mean of Dependent Variable in 2002 & 0.25 & 0.25 & & \\
\hline Baseline Opioid * Year Effects & No & Yes & No & Yes \\
\hline State Linear Trend & No & No & No & No \\
\hline Number of Observations & 765 & 765 & 765 & 765 \\
\hline
\end{tabular}

Notes: We exclude prescriptions for methadone, buprenorphine and fentanyl. The unit of observation is the state-year. Regressions include state fixed effects, year fixed effects and the share of the state population in four-year age categories for ages 15 and older. All regressions are weighted by state population. Standard errors in parentheses. Standard errors were constructed allowing for non-independence (clustering) within state. $* 0.05<\mathrm{p}$-value $\leq 0.10, * * \mathrm{p}$-value $\leq 0.05$ 
Table 3: Estimates of Effects of State Polices on Mortality Rates from All Causes, 2002 to 2016

\begin{tabular}{|c|c|c|c|c|c|c|}
\hline \multirow{3}{*}{ A. Basic Model } & \multicolumn{2}{|c|}{ All Ages } & \multicolumn{2}{|c|}{ Age $18-34$} & \multicolumn{2}{|c|}{ Age 35-64 } \\
\hline & Females & Males & Females & Males & Females & Males \\
\hline & & & & & & \\
\hline Modern PDMP & $\begin{array}{l}-4.764 \\
(2.989)\end{array}$ & $\begin{array}{l}-5.506 \\
(4.511)\end{array}$ & $\begin{array}{c}-2.548^{* *} \\
(1.169)\end{array}$ & $\begin{array}{l}-4.505^{*} \\
(2.329)\end{array}$ & $\begin{array}{l}-7.253^{*} \\
(4.255)\end{array}$ & $\begin{array}{l}-8.329 \\
(6.431)\end{array}$ \\
\hline Pill Mill & $\begin{array}{l}9.860 \\
(7.317)\end{array}$ & $\begin{array}{c}3.976 \\
(10.919)\end{array}$ & $\begin{array}{l}-0.614 \\
(3.075)\end{array}$ & $\begin{array}{l}-4.809 \\
(5.787)\end{array}$ & $\begin{array}{c}14.605 \\
(10.683)\end{array}$ & $\begin{array}{c}7.922 \\
(15.506)\end{array}$ \\
\hline $\begin{array}{l}\text { B. Model with Baseline } \\
\text { Opioid Interactions }\end{array}$ & & & & & & \\
\hline Modern PDMP & $\begin{array}{l}-2.709 \\
(2.671)\end{array}$ & $\begin{array}{l}-2.706 \\
(4.564)\end{array}$ & $\begin{array}{l}-1.511 \\
(1.123)\end{array}$ & $\begin{array}{l}-3.060 \\
(3.033)\end{array}$ & $\begin{array}{l}-4.527 \\
(3.727)\end{array}$ & $\begin{array}{l}-4.422 \\
(5.902)\end{array}$ \\
\hline Pill Mill & $\begin{array}{l}9.297 * \\
(5.269)\end{array}$ & $\begin{array}{c}3.898 \\
(8.452)\end{array}$ & $\begin{array}{l}-1.215 \\
(2.498)\end{array}$ & $\begin{array}{l}-5.887 \\
(4.909)\end{array}$ & $\begin{array}{l}13.171 * \\
(7.381)\end{array}$ & $\begin{array}{c}6.563 \\
(11.498)\end{array}$ \\
\hline Mean of Dependent Variable & 215.94 & 375.09 & 61.04 & 147.31 & 370.84 & 602.80 \\
\hline Number of Observations & 1,530 & 1,530 & 765 & 765 & 765 & 765 \\
\hline
\end{tabular}

Notes: The unit of observation is the state-year mortality rate (per 100,000) for the demographic groups listed in the tables. All regression models include state and year fixed effects. Panel B, add the interactions between baseline opioid sales and year effects. All regressions are weighted by state population. Standard errors in parentheses. Standard errors were constructed allowing for non-independence (clustering) within state. $* 0.05<\mathrm{p}$-value $\leq$ $0.10, * *$ p-value $\leq 0.05$ 
Table 4: Estimates of Effects of State Polices on Mortality Rates from Drug-related Causes, 2002 to 2016

\begin{tabular}{lcccccc}
\hline & \multicolumn{2}{c}{ All Ages } & \multicolumn{2}{c}{ Age 18-34 } & \multicolumn{2}{c}{ Age 35-64 } \\
& Females & Males & Females & Males & Females & Males \\
\hline A. Basic Model & & & & & & \\
Modern PDMP & $-1.783^{*}$ & $-3.167^{*}$ & $-1.934^{* *}$ & $-3.012^{*}$ & $-1.719^{*}$ & $-3.303^{*}$ \\
& $(0.921)$ & $(1.646)$ & $(0.952)$ & $(1.782)$ & $(0.987)$ & $(1.727)$ \\
Pill Mill & & & & & & \\
& 0.542 & -0.538 & -0.173 & -3.294 & 0.937 & 1.126 \\
& $(2.375)$ & $(4.691)$ & $(2.362)$ & $(4.847)$ & $(2.542)$ & $(4.868)$ \\
\hline B. Model with Baseline & & & & & & \\
$\quad$ Opioid Interactions & & & & & & \\
Modern PDMP & -0.956 & -1.505 & $-1.161^{*}$ & -1.601 & -0.862 & -1.482 \\
& $(0.628)$ & $(1.139)$ & $(0.644)$ & $(1.246)$ & $(0.751)$ & $(1.355)$ \\
Pill Mill & & & & & & \\
& -0.153 & -1.739 & -0.915 & -4.536 & 0.245 & -0.117 \\
& $(1.477)$ & $(3.150)$ & $(1.624)$ & $(3.637)$ & $(1.611)$ & $(3.245)$ \\
\hline $\begin{array}{l}\text { Mean of Dependent Variable } \\
\text { Number of Observations }\end{array}$ & 13.42 & 24.69 & 8.34 & 21.70 & 18.49 & 27.67 \\
\hline
\end{tabular}

Notes: The unit of observation is the state-year mortality rate (per 100,000) for the demographic groups listed in the tables. Drug-related causes include underlying-cause-of-death ICD-10 code of X40-X44 (drug poisonings, unintentional), X60-X64 (drug poisonings, suicide), X85 (drug poisonings, homicide), and Y10-Y14 (drug poisonings, undetermined intent). All regression models include state and year fixed effects. Panel $\mathrm{B}$, adds the interactions between baseline opioid sales and year effects. All regressions are weighted by state population. Standard errors in parentheses. Standard errors were constructed allowing for non-independence (clustering) within state. ${ }^{*} 0.05<\mathrm{p}$-value $\leq 0.10, * *$ p-value $\leq 0.05$ 
Table 5: Estimates of Effects of State Polices on Probability of Being Employed at Time of Survey, 2002 to 2016

\begin{tabular}{|c|c|c|c|c|c|c|}
\hline \multirow{3}{*}{ A. Basic Model } & \multicolumn{2}{|c|}{ All Ages } & \multicolumn{2}{|c|}{ Age 18-34 } & \multicolumn{2}{|c|}{ Age 35-64 } \\
\hline & Females & Males & Females & Males & Females & Males \\
\hline & & & & & & \\
\hline Modern PDMP & $\begin{array}{l}-0.003 \\
(0.002)\end{array}$ & $\begin{array}{c}-0.006^{* *} \\
(0.003)\end{array}$ & $\begin{array}{l}-0.005 * \\
(0.003)\end{array}$ & $\begin{array}{c}-0.012 * * \\
(0.004)\end{array}$ & $\begin{array}{l}-0.003 \\
(0.002)\end{array}$ & $\begin{array}{l}-0.003 \\
(0.003)\end{array}$ \\
\hline Pill Mill & $\begin{array}{c}0.001 \\
(0.002)\end{array}$ & $\begin{array}{c}0.003 \\
(0.003)\end{array}$ & $\begin{array}{c}0.004 \\
(0.003)\end{array}$ & $\begin{array}{c}0.006 \\
(0.006)\end{array}$ & $\begin{array}{l}-0.001 \\
(0.003)\end{array}$ & $\begin{array}{c}0.002 \\
(0.003)\end{array}$ \\
\hline $\begin{array}{l}\text { B. Model with Baseline } \\
\text { Opioid Interactions }\end{array}$ & & & & & & \\
\hline Modern PDMP & $\begin{array}{c}-0.004^{* *} \\
(0.002)\end{array}$ & $\begin{array}{c}-0.007^{* *} \\
(0.003)\end{array}$ & $\begin{array}{c}-0.005^{* *} \\
(0.002)\end{array}$ & $\begin{array}{c}-0.011^{* *} \\
(0.004)\end{array}$ & $\begin{array}{c}-0.004^{* *} \\
(0.001)\end{array}$ & $\begin{array}{l}-0.004^{*} \\
(0.002)\end{array}$ \\
\hline Pill Mill & $\begin{array}{c}0.001 \\
(0.002)\end{array}$ & $\begin{array}{c}0.005 \\
(0.003)\end{array}$ & $\begin{array}{l}0.005^{*} \\
(0.003)\end{array}$ & $\begin{array}{c}0.008 \\
(0.006)\end{array}$ & $\begin{array}{l}-0.001 \\
(0.002)\end{array}$ & $\begin{array}{c}0.002 \\
(0.002)\end{array}$ \\
\hline Mean of Dependent Variable & 0.618 & 0.733 & 0.612 & 0.722 & 0.621 & 0.739 \\
\hline Number of Observations & 445,376 & 440,063 & 159,686 & 158,513 & 285,690 & 281,550 \\
\hline
\end{tabular}

Notes: The unit of observation is the state-year-group (age-by female-by education). All regression models include state and year fixed effects, dummy variables for each year of age and dummy variables for race/ethnicity (non-Hispanic white, non-Hispanic black, Hispanic, and non-Hispanic other), dummy variables for education categories (less than high school, high school, some college, 4 year college or more), interactions of the education categories and year effects and interactions of the race categories and year effects. Panel B, adds the interactions between baseline opioid sales and year effects. All regressions are weighted by the number of individuals in a group. Standard errors in parentheses. Standard errors were constructed allowing for non-independence (clustering) within state. $* 0.05<\mathrm{p}$-value $\leq 0.10, * * \mathrm{p}$-value $\leq 0.05$ 
Table 6: Estimates of Effects of State Polices on Probability of Working >=48 Weeks Past 12 Months, 2002 to 2016

\begin{tabular}{|c|c|c|c|c|c|c|}
\hline & \multicolumn{2}{|c|}{ All Ages } & \multicolumn{2}{|c|}{ Age 18-34 } & \multicolumn{2}{|c|}{ Age 35-64 } \\
\hline & Females & Males & Females & Males & Females & Males \\
\hline \multicolumn{7}{|l|}{ A. Basic Model } \\
\hline \multirow[t]{2}{*}{ Modern PDMP } & $-0.004^{* *}$ & $-0.008 * *$ & $-0.004 *$ & $-0.013 * *$ & $-0.004 * *$ & -0.005 \\
\hline & $(0.002)$ & $(0.003)$ & $(0.002)$ & $(0.004)$ & $(0.002)$ & $(0.003)$ \\
\hline \multirow[t]{2}{*}{ Pill Mill } & 0.004 & 0.005 & $0.007^{*}$ & 0.008 & 0.003 & 0.004 \\
\hline & $(0.003)$ & $(0.004)$ & $(0.004)$ & $(0.007)$ & $(0.002)$ & $(0.004)$ \\
\hline \multicolumn{7}{|l|}{$\begin{array}{l}\text { B. Model with Baseline } \\
\text { Opioid Interactions }\end{array}$} \\
\hline \multirow[t]{2}{*}{ Modern PDMP } & $-0.004 * *$ & $-0.008 * *$ & -0.003 & $-0.012 * *$ & $-0.004 * *$ & $-0.005 *$ \\
\hline & $(0.002)$ & $(0.003)$ & $(0.002)$ & $(0.004)$ & $(0.002)$ & $(0.003)$ \\
\hline \multirow[t]{2}{*}{ Pill Mill } & $0.006 * *$ & 0.006 & $0.009 * *$ & 0.010 & $0.004 * *$ & 0.004 \\
\hline & $(0.002)$ & $(0.004)$ & $(0.004)$ & $(0.006)$ & $(0.002)$ & $(0.003)$ \\
\hline Mean of Dependent Variable & 0.499 & 0.626 & 0.451 & 0.568 & 0.527 & 0.659 \\
\hline Number of Observations & 445,376 & 440,063 & 159,686 & 158,513 & 285,690 & 281,550 \\
\hline
\end{tabular}

Notes: The unit of observation is the state-year-group (age-by female-by education). All regression models include state and year fixed effects, dummy variables for each year of age and dummy variables for race/ethnicity (non-Hispanic white, non-Hispanic black, Hispanic, and non-Hispanic other), dummy variables for education categories (less than high school, high school, some college, 4 year college or more), interactions of the education categories and year effects and interactions of the race categories and year effects. Panel B, adds the interactions between baseline opioid sales and year effects. All regressions are weighted by the number of individuals in a group. Standard errors in parentheses. Standard errors were constructed allowing for non-independence (clustering) within state. ${ }^{*} 0.05<\mathrm{p}$-value $\leq 0.10, * *$ p-value $\leq 0.05$ 
Table 7: Estimates of Effects of State Polices on Earnings (in \$1,000 of 2010\$) in past 12 month, 2002 to 2016

\begin{tabular}{|c|c|c|c|c|c|c|}
\hline & \multicolumn{2}{|c|}{ All Ages } & \multicolumn{2}{|c|}{ Age 18-34 } & \multicolumn{2}{|c|}{ Age 35-64 } \\
\hline & Females & Males & Females & Males & Females & Males \\
\hline \multicolumn{7}{|l|}{ A. Basic Model } \\
\hline \multirow[t]{2}{*}{ Modern PDMP } & -0.231 & $-0.426^{*}$ & -0.252 & $-0.579 * *$ & -0.177 & -0.232 \\
\hline & $(0.157)$ & $(0.253)$ & $(0.159)$ & $(0.281)$ & $(0.171)$ & $(0.261)$ \\
\hline \multirow[t]{2}{*}{ Pill Mill } & -0.229 & 0.361 & 0.215 & 0.769 & -0.430 & 0.137 \\
\hline & $(0.278)$ & $(0.785)$ & $(0.309)$ & $(0.712)$ & $(0.322)$ & $(0.941)$ \\
\hline \multicolumn{7}{|l|}{$\begin{array}{l}\text { B. Model with Baseline Opioid } \\
\text { Interactions }\end{array}$} \\
\hline \multirow[t]{2}{*}{ Modern PDMP } & -0.197 & -0.418 & -0.199 & $-0.576^{*}$ & -0.217 & -0.345 \\
\hline & $(0.159)$ & $(0.311)$ & $(0.150)$ & $(0.303)$ & $(0.191)$ & $(0.341)$ \\
\hline \multirow[t]{2}{*}{ Pill Mill } & -0.000 & 0.806 & 0.331 & 0.995 & -0.157 & 0.627 \\
\hline & $(0.267)$ & $(0.719)$ & $(0.274)$ & $(0.655)$ & $(0.286)$ & $(0.772)$ \\
\hline Mean of Dependent Variable & 19.935 & 33.439 & 14.914 & 22.881 & 22.742 & 39.383 \\
\hline Standard Deviation of Dependent Variable & 19.09 & 30.10 & 13.29 & 19.09 & 20.33 & 33.33 \\
\hline Number of Observations & 445,376 & 440,063 & 159,686 & 158,513 & 285,690 & 281,550 \\
\hline \multicolumn{7}{|c|}{$\begin{array}{l}\text { Notes: The unit of observation is the state-year-group (age-by female-by education). All regression models include state and year } \\
\text { fixed effects, dummy variables for each year of age and dummy variables for race/ethnicity (non-Hispanic white, non-Hispanic } \\
\text { black, Hispanic, and non-Hispanic other), dummy variables for education categories (less than high school, high school, some } \\
\text { college, } 4 \text { year college or more), interactions of the education categories and year effects and interactions of the race categories } \\
\text { and year effects. Panel B, adds the interactions between baseline opioid sales and year effects. All regressions are } \\
\text { weighted by the number of individuals in a group. Standard errors in parentheses. Standard errors were } \\
\text { constructed allowing for non-independence (clustering) within state. } * 0.05<\text { p-value } \leq 0.10, * * \text { p-value } \leq 0.05\end{array}$} \\
\hline
\end{tabular}


Table 8: Estimates of Effects of State Polices on Probability of Receipt of Any Public Assistance past 12 Months 2002 to 2016

\begin{tabular}{|c|c|c|c|c|c|c|}
\hline & \multicolumn{2}{|c|}{ All Ages } & \multicolumn{2}{|c|}{ Age 18-34 } & \multicolumn{2}{|c|}{ Age 35-64 } \\
\hline & Females & Males & Females & Males & Females & Males \\
\hline \multicolumn{7}{|l|}{ A. Basic Model } \\
\hline \multirow[t]{2}{*}{ Modern PDMP } & 0.001 & 0.000 & $0.002 * *$ & 0.001 & -0.000 & -0.000 \\
\hline & $(0.001)$ & $(0.001)$ & $(0.001)$ & $(0.001)$ & $(0.001)$ & $(0.001)$ \\
\hline \multirow[t]{2}{*}{ Pill Mill } & 0.002 & 0.001 & 0.001 & 0.000 & 0.003 & 0.002 \\
\hline & $(0.002)$ & $(0.001)$ & $(0.002)$ & $(0.001)$ & $(0.002)$ & $(0.002)$ \\
\hline \multicolumn{7}{|l|}{$\begin{array}{l}\text { B. Model with Baseline } \\
\text { Opioid Interactions }\end{array}$} \\
\hline \multirow[t]{2}{*}{ Modern PDMP } & $0.001 * *$ & 0.001 & $0.002 *$ & 0.001 & $0.001 * *$ & 0.001 \\
\hline & $(0.001)$ & $(0.001)$ & $(0.001)$ & $(0.001)$ & $(0.001)$ & $(0.001)$ \\
\hline \multirow[t]{2}{*}{ Pill Mill } & 0.001 & 0.001 & 0.000 & -0.000 & $0.002 *$ & 0.001 \\
\hline & $(0.001)$ & $(0.001)$ & $(0.002)$ & $(0.001)$ & $(0.001)$ & $(0.001)$ \\
\hline \multirow{2}{*}{$\begin{array}{l}\text { Mean of Dependent Variable } \\
\text { Number of Observations }\end{array}$} & 0.057 & 0.031 & 0.058 & 0.021 & 0.056 & 0.036 \\
\hline & 445,376 & 440,063 & 159,686 & 158,513 & 285,690 & 281,550 \\
\hline
\end{tabular}

Notes: The unit of observation is the state-year-group (age-by female-by education). All regression models include state and year fixed effects, dummy variables for each year of age and dummy variables for race/ethnicity (non-Hispanic white, non-Hispanic black, Hispanic, and non-Hispanic other), dummy variables for education categories (less than high school, high school, some college, 4 year college or more), interactions of the education categories and year effects and interactions of the race categories and year effects. Panel B, adds the interactions between baseline opioid sales and year effects. All regressions are weighted by the number of individuals in a group. Standard errors in parentheses. Standard errors were constructed allowing for non-independence (clustering) within state. ${ }^{*} 0.05<\mathrm{p}$-value $\leq 0.10, * * \mathrm{p}$-value $\leq 0.05$ 
Table 9: Estimates of Effects of State Polices on Probability of Married and Living with Spouse, 2002 to 2016

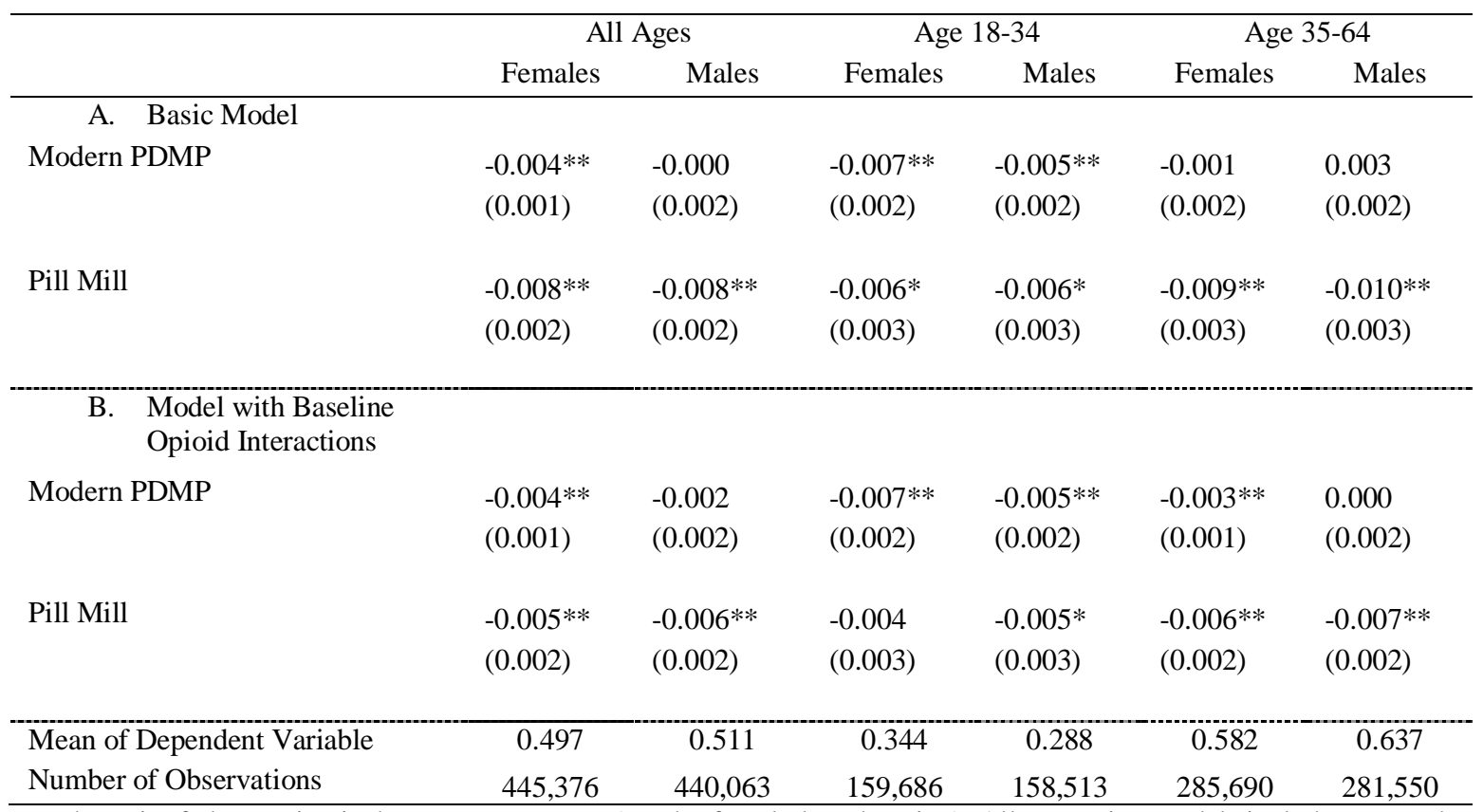

Notes: The unit of observation is the state-year-group (age-by female-by education). All regression models include state and year fixed effects, dummy variables for each year of age and dummy variables for race/ethnicity (non-Hispanic white, non-Hispanic black, Hispanic, and non-Hispanic other), dummy variables for education categories (less than high school, high school, some college, 4 year college or more), interactions of the education categories and year effects and interactions of the race categories and year effects. Panel B, adds the interactions between baseline opioid sales and year effects. All regressions are weighted by the number of individuals in a group. Standard errors in parentheses. Standard errors were constructed allowing for non-independence (clustering) within state. $* 0.05<\mathrm{p}$-value $\leq 0.10, * * \mathrm{p}$-value $\leq 0.05$ 
Table 10: Estimates of Effects of State Polices on Probability of Any Cognitive or Ambulatory Difficulty, 2002 to 2016

\begin{tabular}{|c|c|c|c|c|c|c|}
\hline \multirow{3}{*}{ A. Basic Model } & \multicolumn{2}{|c|}{ All Ages } & \multicolumn{2}{|c|}{ Age 18-34 } & \multicolumn{2}{|c|}{ Age 35-64 } \\
\hline & Females & Males & Females & Males & Females & Males \\
\hline & & & & & & \\
\hline \multirow[t]{2}{*}{ Modern PDMP } & -0.002 & 0.000 & -0.001 & 0.001 & -0.002 & -0.000 \\
\hline & $(0.001)$ & $(0.001)$ & $(0.001)$ & $(0.001)$ & $(0.002)$ & $(0.002)$ \\
\hline \multirow[t]{2}{*}{ Pill Mill } & 0.000 & -0.001 & 0.000 & -0.001 & 0.000 & -0.001 \\
\hline & $(0.001)$ & $(0.001)$ & $(0.001)$ & $(0.001)$ & $(0.002)$ & $(0.002)$ \\
\hline \multicolumn{7}{|c|}{$\begin{array}{l}\text { B. Model with Baseline Opioid } \\
\text { Interactions }\end{array}$} \\
\hline \multirow[t]{2}{*}{ Modern PDMP } & -0.000 & 0.001 & -0.001 & 0.001 & -0.000 & 0.001 \\
\hline & $(0.001)$ & $(0.001)$ & $(0.001)$ & $(0.001)$ & $(0.001)$ & $(0.001)$ \\
\hline \multirow[t]{2}{*}{ Pill Mill } & -0.000 & -0.002 & -0.001 & -0.002 & 0.000 & -0.001 \\
\hline & $(0.001)$ & $(0.001)$ & $(0.001)$ & $(0.001)$ & $(0.001)$ & $(0.002)$ \\
\hline Mean of Dependent Variable & 0.139 & 0.135 & 0.074 & 0.079 & 0.176 & 0.167 \\
\hline Number of Observations & 445,376 & 440,063 & 159,686 & 158,513 & 285,690 & 281,550 \\
\hline
\end{tabular}


Figure 1: State Opioid Policies over Time

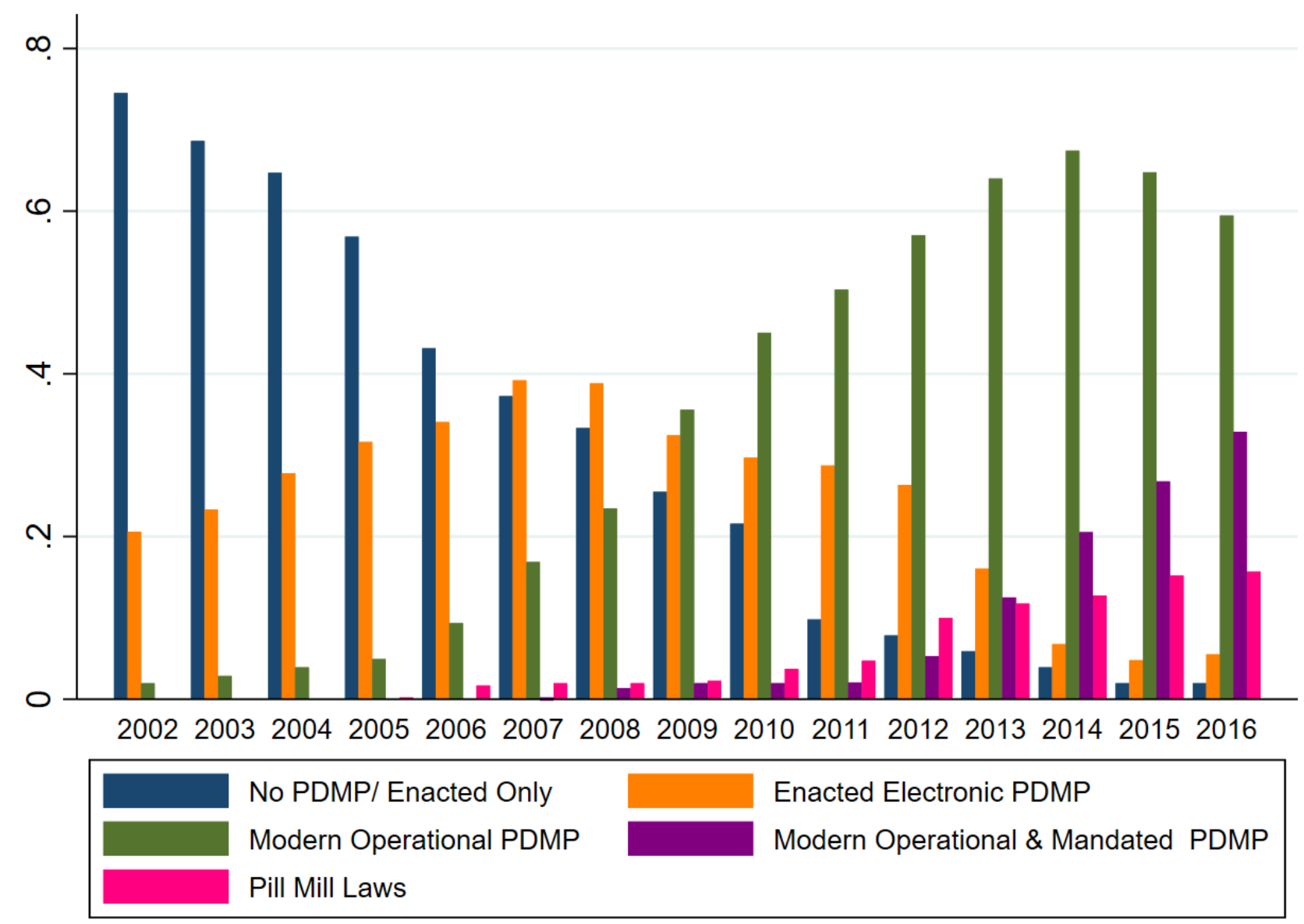


Figure 2: Event Study Coefficients of the Modern Operational Prescription Drug Monitoring Programs (PDMPs) on Log Per Capita and Per Capita Opioid Sales 2002-2016

A. All Drugs

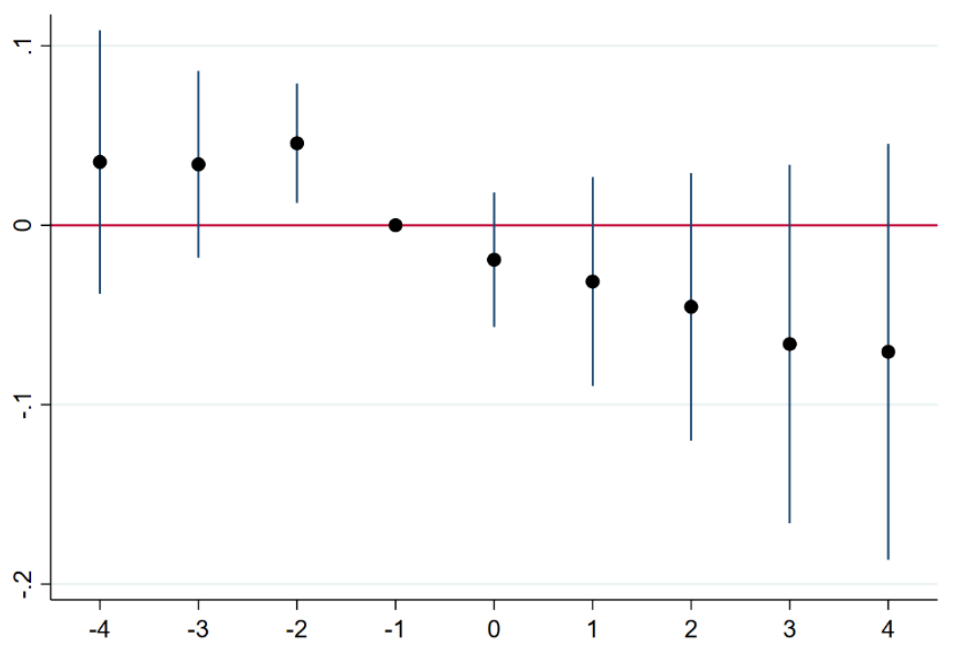

log per-capita

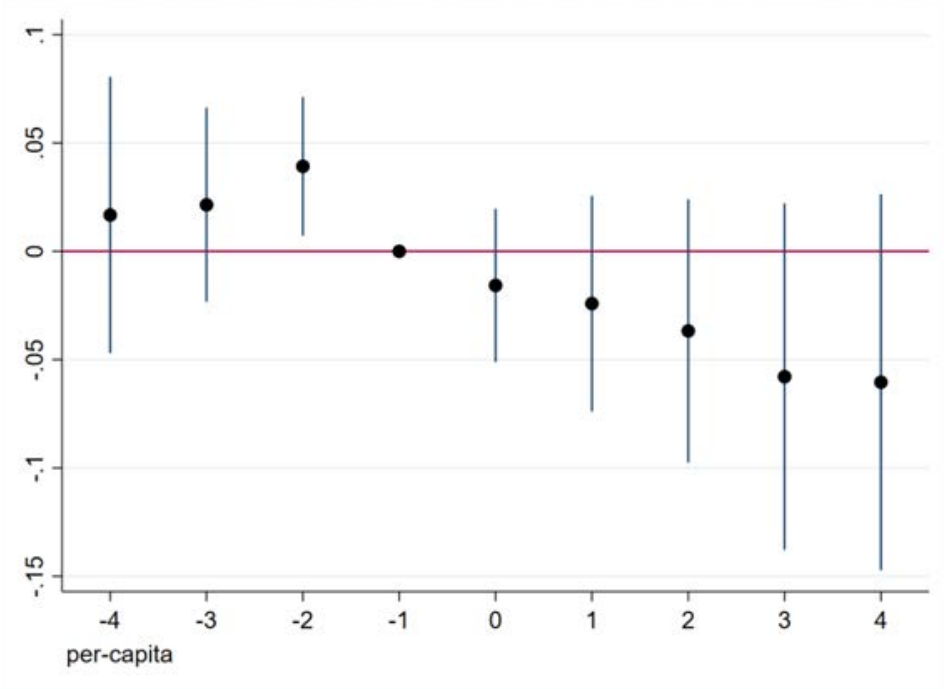

B. Hydrocodone/Oxycodone
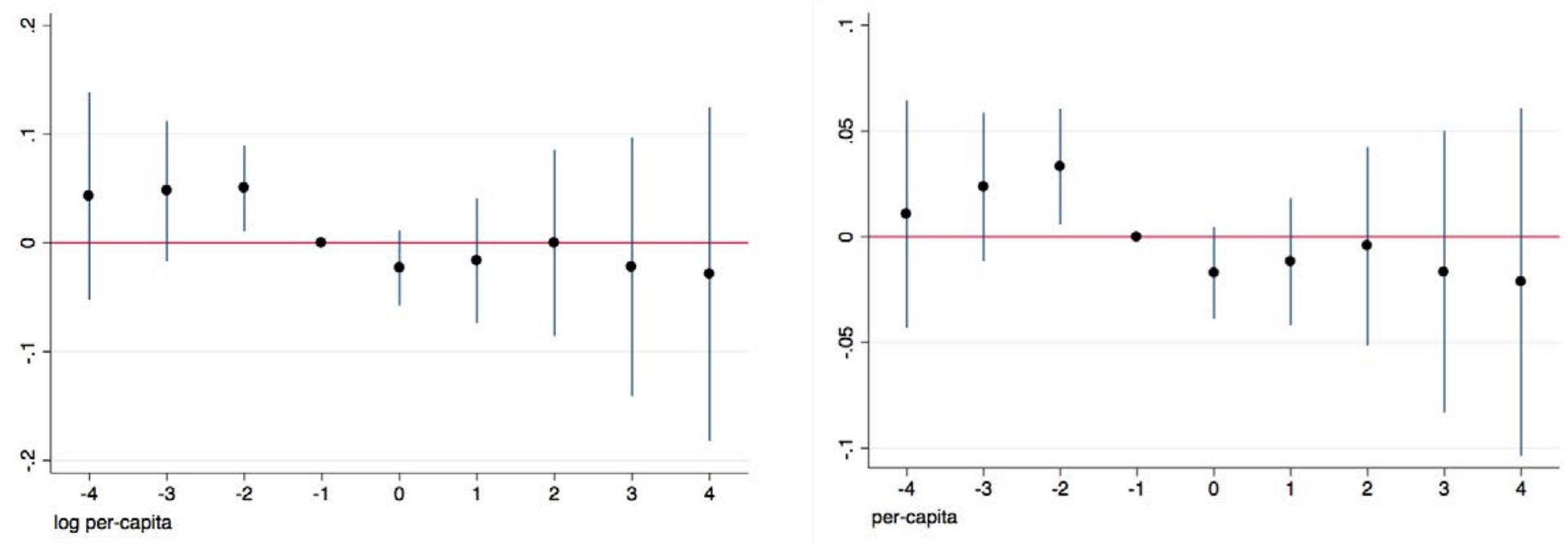
Figure 3: Event Study Coefficients of the Pill Mill Laws on Log Per Capita and Per Capita Opioid Sales 2002-2016
A. All Drugs
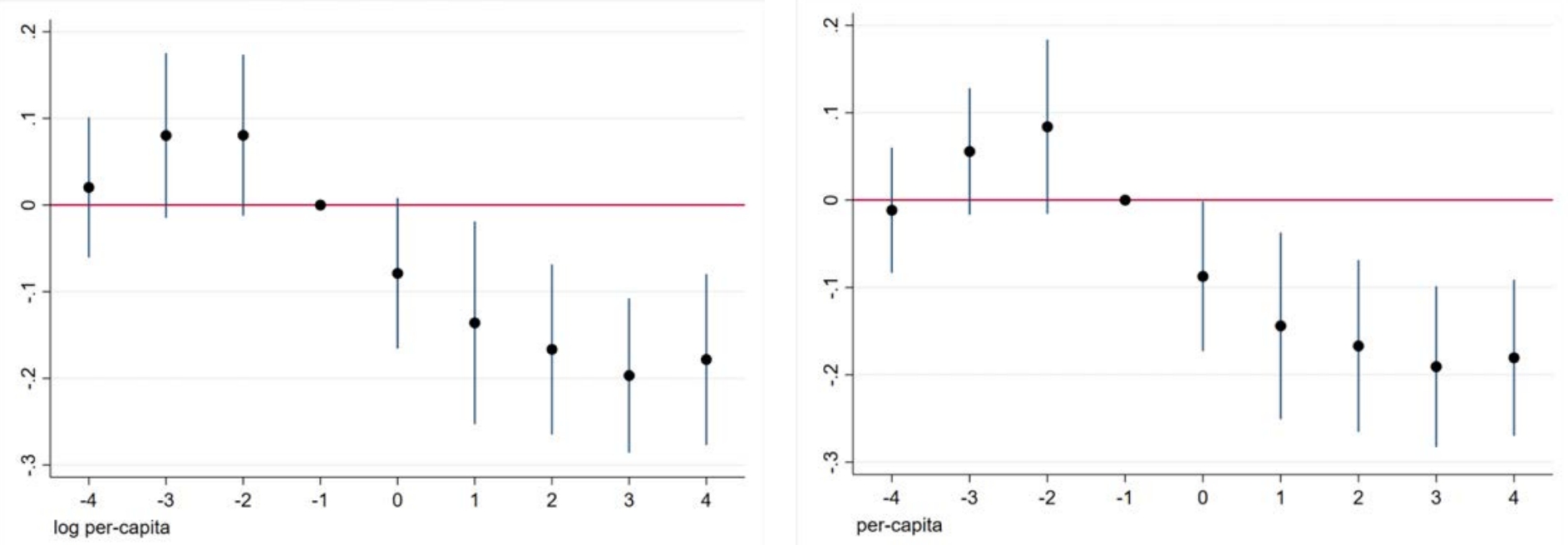

B. Hydrocodone/Oxycodone
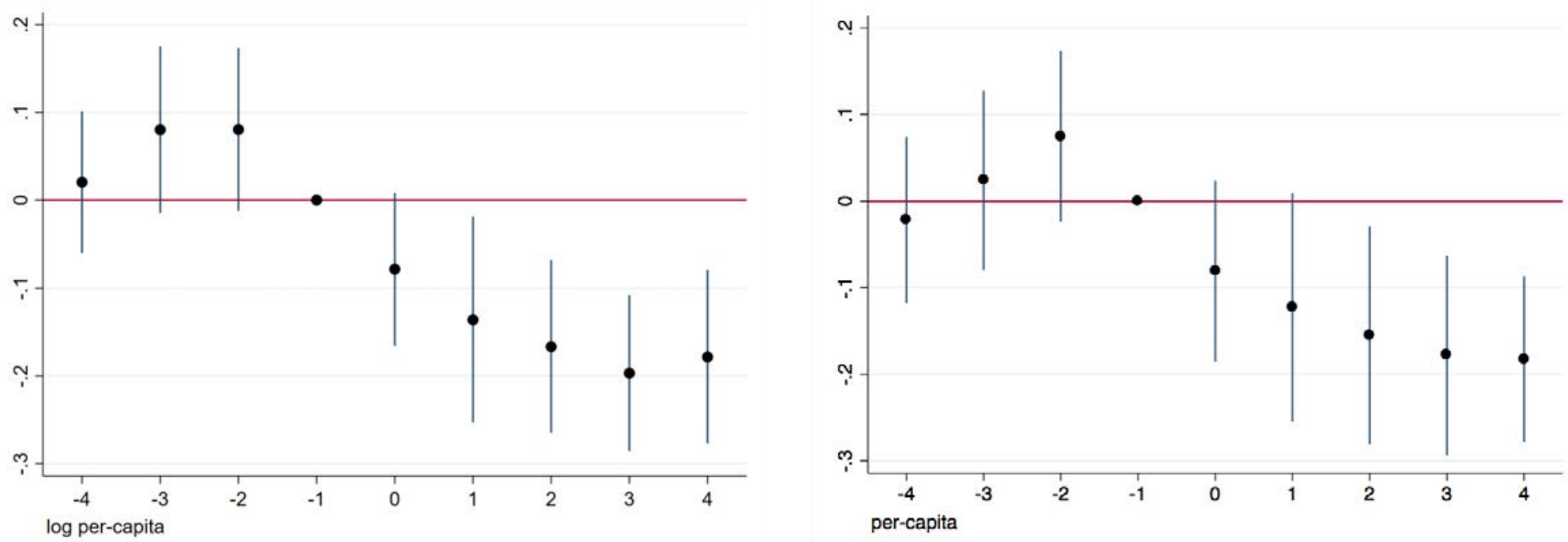
Appendix Table 1: First Stage Sales Expanded Definition

\begin{tabular}{|c|c|c|}
\hline All Opioids & $\begin{array}{c}\text { Per-capita MEG Grams } \\
(1)\end{array}$ & $\begin{array}{c}\text { Log Per Capita MEG Grams } \\
(2)\end{array}$ \\
\hline Electronic & $\begin{array}{c}0.011 \\
(0.023)\end{array}$ & $\begin{array}{c}0.036 \\
(0.027)\end{array}$ \\
\hline Modern without Mandate & $\begin{array}{l}-0.029 \\
(0.036)\end{array}$ & $\begin{array}{l}-0.021 \\
(0.039)\end{array}$ \\
\hline Modern with Mandate & $\begin{array}{l}-0.034 \\
(0.036)\end{array}$ & $\begin{array}{l}-0.050 \\
(0.044)\end{array}$ \\
\hline Pill Mill & $\begin{array}{c}-0.124^{* *} \\
(0.031)\end{array}$ & $\begin{array}{c}-0.153^{* *} \\
(0.036)\end{array}$ \\
\hline P-value of F-Test of Joint Significance & 0.00 & 0.00 \\
\hline Mean of Dependent Variable in 2002 & 0.39 & \\
\hline Hydrocodone/Oxycodone & & \\
\hline Electronic & $\begin{array}{c}0.002 \\
(0.023)\end{array}$ & $\begin{array}{c}0.029 \\
(0.033)\end{array}$ \\
\hline Modern without Mandate & $\begin{array}{l}-0.038 \\
(0.028)\end{array}$ & $\begin{array}{c}-0.060 \\
(0.038)\end{array}$ \\
\hline Modern with Mandate & $\begin{array}{l}-0.001 \\
(0.033)\end{array}$ & $\begin{array}{c}0.011 \\
(0.058)\end{array}$ \\
\hline Pill Mill & $\begin{array}{c}-0.131^{* *} \\
(0.036)\end{array}$ & $\begin{array}{c}-0.221 * * \\
(0.055)\end{array}$ \\
\hline P-value of F-Test of Joint Significance & 0.00 & 0.00 \\
\hline Mean of Dependent Variable in 2002 & 0.25 & 0.25 \\
\hline $\begin{array}{l}\text { Baseline Opioid * Year Effects } \\
\text { State Linear Trend } \\
\text { Number of Observations }\end{array}$ & $\begin{array}{l}\text { Yes } \\
\text { No } \\
765\end{array}$ & $\begin{array}{l}\text { Yes } \\
\text { No } \\
765\end{array}$ \\
\hline
\end{tabular}

Notes: We exclude prescriptions for methadone, buprenorphine and fentanyl. The unit of observation is the state-year. Regressions include state fixed effects, year fixed effects and the share of the state population in four-year age categories for ages 15 and older. All regressions are weighted by state population. Standard errors in parentheses. Standard errors were constructed allowing for non-independence (clustering) within state. $* 0.05<\mathrm{p}$-value $\leq 0.10, * *$ p-value $\leq 0.05$ 
Appendix Table 2: Estimates of Effects of State Polices on Probability of Being Employed at Time of Survey, 2002 to 2016 Sample of Persons with 12 or Fewer Years of Education

\begin{tabular}{|c|c|c|c|c|c|c|}
\hline & \multicolumn{2}{|c|}{ All Ages } & \multicolumn{2}{|c|}{ Age 18-34 } & \multicolumn{2}{|c|}{ Age 35-64 } \\
\hline & Females & Males & Females & Males & Females & Males \\
\hline \multicolumn{7}{|l|}{ A. Basic Model } \\
\hline Modern PDMP & -0.004 & $-0.008 * *$ & $-0.006 *$ & $-0.015^{* *}$ & -0.002 & -0.003 \\
\hline & $(0.003)$ & $(0.004)$ & $(0.004)$ & $(0.005)$ & $(0.003)$ & $(0.004)$ \\
\hline Pill Mill & $\begin{array}{c}0.004 \\
(0.004)\end{array}$ & $\begin{array}{c}0.007 \\
(0.005)\end{array}$ & $\begin{array}{c}0.012 * * \\
(0.006)\end{array}$ & $\begin{array}{l}0.014 * \\
(0.008)\end{array}$ & $\begin{array}{l}-0.000 \\
(0.004)\end{array}$ & $\begin{array}{c}0.004 \\
(0.006)\end{array}$ \\
\hline \multicolumn{7}{|l|}{$\begin{array}{l}\text { Model with Baseline } \\
\text { Opioid Interactions }\end{array}$} \\
\hline Modern PDMP & $\begin{array}{c}-0.006^{* *} \\
(0.002)\end{array}$ & $\begin{array}{c}-0.010 * * \\
(0.003)\end{array}$ & $\begin{array}{l}-0.007 * \\
(0.004)\end{array}$ & $\begin{array}{c}-0.014 * * \\
(0.005)\end{array}$ & $\begin{array}{c}-0.005^{* *} \\
(0.002)\end{array}$ & $\begin{array}{c}-0.007 * * \\
(0.003)\end{array}$ \\
\hline Pill Mill & $\begin{array}{c}0.003 \\
(0.003)\end{array}$ & $\begin{array}{l}0.008^{*} \\
(0.004)\end{array}$ & $\begin{array}{c}0.009 * * \\
(0.004)\end{array}$ & $\begin{array}{l}0.013^{*} \\
(0.007)\end{array}$ & $\begin{array}{c}0.000 \\
(0.003)\end{array}$ & $\begin{array}{c}0.004 \\
(0.003)\end{array}$ \\
\hline Mean of Dependent Variable & 0.518 & 0.659 & 0.505 & 0.655 & 0.526 & 0.662 \\
\hline Number of Observations & 223,528 & 223,484 & 81,515 & 83,059 & 142,013 & 140,425 \\
\hline
\end{tabular}

Notes: The unit of observation is the state-year-group (age-by female). All regression models include state and year fixed effects, dummy variables for each year of age and dummy variables for race/ethnicity (non-Hispanic white, non-Hispanic black, Hispanic, and non-Hispanic other), interactions of the race categories and year effects. Panel B, adds the interactions between baseline opioid sales and year effects. All regressions are weighted by the number of individuals in a group. Standard errors in parentheses. Standard errors were constructed allowing for non-independence (clustering) within state. $* 0.05<\mathrm{p}$-value $\leq 0.10, * * \mathrm{p}$-value $\leq 0.05$ 
Appendix Table 3: Estimates of Effects of State Polices on Probability of Working 48 or more Weeks Past 12 Months, 2002 to 2016 Sample of Persons with 12 or Fewer Years of Education

\begin{tabular}{|c|c|c|c|c|c|c|}
\hline & \multicolumn{2}{|c|}{ All Ages } & \multicolumn{2}{|c|}{ Age 18-34 } & \multicolumn{2}{|c|}{ Age 35-64 } \\
\hline & Females & Males & Females & Males & Females & Males \\
\hline A. Basic Model & & & & & & \\
\hline Modern PDMP & $\begin{array}{c}-0.004 * \\
(0.002)\end{array}$ & $\begin{array}{c}-0.008^{* *} \\
(0.004)\end{array}$ & $\begin{array}{l}-0.004 \\
(0.002)\end{array}$ & $\begin{array}{c}-0.013^{* *} \\
(0.004)\end{array}$ & $\begin{array}{l}-0.004 \\
(0.002)\end{array}$ & $\begin{array}{l}-0.005 \\
(0.004)\end{array}$ \\
\hline Pill Mill & $\begin{array}{l}0.008^{*} \\
(0.004)\end{array}$ & $\begin{array}{c}0.011 \\
(0.006)\end{array}$ & $\begin{array}{c}0.015^{* *} \\
(0.006)\end{array}$ & $\begin{array}{c}0.018 * * \\
(0.008)\end{array}$ & $\begin{array}{c}0.004 \\
(0.004)\end{array}$ & $\begin{array}{c}0.007 \\
(0.007)\end{array}$ \\
\hline $\begin{array}{l}\text { B. Model with Baseline } \\
\text { Opioid Interactions }\end{array}$ & & & & & & \\
\hline Modern PDMP & $\begin{array}{c}-0.004^{* *} \\
(0.002)\end{array}$ & $\begin{array}{c}-0.010 * * \\
(0.004)\end{array}$ & $\begin{array}{l}-0.004 \\
(0.003)\end{array}$ & $\begin{array}{c}-0.013^{* *} \\
(0.004)\end{array}$ & $\begin{array}{c}-0.004^{* *} \\
(0.002)\end{array}$ & $\begin{array}{c}-0.007^{* *} \\
(0.004)\end{array}$ \\
\hline Pill Mill & $\begin{array}{c}0.007 * * \\
(0.003)\end{array}$ & $\begin{array}{c}0.011^{* *} \\
(0.006)\end{array}$ & $\begin{array}{c}0.013 * * \\
(0.005)\end{array}$ & $\begin{array}{c}0.018 * * \\
(0.008)\end{array}$ & $\begin{array}{c}0.004 \\
(0.003)\end{array}$ & $\begin{array}{c}0.007 \\
(0.005)\end{array}$ \\
\hline Mean of Dependent Variable & 0.415 & 0.548 & 0.360 & 0.502 & 0.447 & 0.576 \\
\hline Number of Observations & 223,528 & 223,484 & 81,515 & 83,059 & 142,013 & 140,425 \\
\hline
\end{tabular}

Notes: The unit of observation is the state-year-group (age-by female). All regression models include state and year fixed effects, dummy variables for each year of age and dummy variables for race/ethnicity (non-Hispanic white, non-Hispanic black, Hispanic, and non-Hispanic other), interactions of the race categories and year effects. Panel B, adds the interactions between baseline opioid sales and year effects. All regressions are weighted by the number of individuals in a group. Standard errors in parentheses. Standard errors were constructed allowing for non-independence (clustering) within state. $* 0.05<\mathrm{p}$-value $\leq 0.10, * * \mathrm{p}$-value $\leq 0.05$ 
Appendix Table 4: Estimates of Effects of State Polices on Earned Income (2010 dollars in \$1,000) in past 12 month 2002 to 2016 Sample of Persons with 12 or Fewer Years of Education

\begin{tabular}{|c|c|c|c|c|c|c|}
\hline \multirow{3}{*}{ A. $\quad$ Basic Model } & \multicolumn{2}{|c|}{ All Ages } & \multicolumn{2}{|c|}{ Age 18-34 } & \multicolumn{2}{|c|}{ Age 35-64 } \\
\hline & Females & Males & Females & Males & Females & Males \\
\hline & & & & & & \\
\hline & $\begin{array}{c}-0.288^{* *} \\
(0.113)\end{array}$ & $\begin{array}{c}-0.596 * * \\
(0.271)\end{array}$ & $\begin{array}{c}-0.211^{* *} \\
(0.099)\end{array}$ & $\begin{array}{c}-0.645^{* *} \\
(0.227)\end{array}$ & $\begin{array}{c}-0.283^{* *} \\
(0.117)\end{array}$ & $\begin{array}{c}-0.513^{*} \\
(0.286)\end{array}$ \\
\hline Pill Mill & $\begin{array}{c}0.201 \\
(0.208)\end{array}$ & $\begin{array}{c}0.782 \\
(0.668)\end{array}$ & $\begin{array}{c}0.459 \\
(0.289)\end{array}$ & $\begin{array}{l}0.968 * \\
(0.573)\end{array}$ & $\begin{array}{c}0.082 \\
(0.198)\end{array}$ & $\begin{array}{c}0.664 \\
(0.747)\end{array}$ \\
\hline $\begin{array}{l}\text { B. Model with Baseline } \\
\text { Opioid Interactions }\end{array}$ & & & & & & \\
\hline Modern PDMP & $\begin{array}{c}-0.325^{* *} \\
(0.119)\end{array}$ & $\begin{array}{c}-0.649 * * \\
(0.289)\end{array}$ & $\begin{array}{c}-0.274^{* *} \\
(0.126)\end{array}$ & $\begin{array}{c}-0.718^{* *} \\
(0.249)\end{array}$ & $\begin{array}{c}-0.329 * * \\
(0.125)\end{array}$ & $\begin{array}{c}-0.593^{*} \\
(0.318)\end{array}$ \\
\hline Pill Mill & $\begin{array}{c}0.190 \\
(0.174)\end{array}$ & $\begin{array}{l}0.931 * \\
(0.530)\end{array}$ & $\begin{array}{l}0.390 * \\
(0.232)\end{array}$ & $\begin{array}{c}1.095 * * \\
(0.484)\end{array}$ & $\begin{array}{c}0.084 \\
(0.174)\end{array}$ & $\begin{array}{c}0.790 \\
(0.566)\end{array}$ \\
\hline Mean of Dependent Variable & 11.781 & 21.288 & 9.310 & 16.638 & 13.199 & 24.039 \\
\hline Number of Observations & 223,528 & 223,484 & 81,515 & 83,059 & 142,013 & 140,425 \\
\hline
\end{tabular}

Notes: The unit of observation is the state-year-group (age-by female). All regression models include state and year fixed effects, dummy variables for each year of age and dummy variables for race/ethnicity (non-Hispanic white, non-Hispanic black, Hispanic, and non-Hispanic other), interactions of the race categories and year effects. Panel B, adds the interactions between baseline opioid sales and year effects. All regressions are weighted by the number of individuals in a group. Standard errors in parentheses. Standard errors were constructed allowing for non-independence (clustering) within state. $* 0.05<\mathrm{p}$-value $\leq 0.10, * * \mathrm{p}$-value $\leq 0.05$ 
Appendix Table 5: Estimates of Effects of State Polices on Probability of Receipt of Any Public Assistance Past 12 Months, 2002 to 2016 Sample of Persons with 12 or Fewer Years of Education

\begin{tabular}{|c|c|c|c|c|c|c|}
\hline & \multicolumn{2}{|c|}{ All Ages } & \multicolumn{2}{|c|}{ Age 18-34 } & \multicolumn{2}{|c|}{ Age 35-64 } \\
\hline & Females & Males & Females & Males & Females & Males \\
\hline \multicolumn{7}{|l|}{ A. Basic Model } \\
\hline \multirow[t]{2}{*}{ Modern PDMP } & 0.000 & -0.000 & $0.003 *$ & 0.000 & -0.001 & -0.000 \\
\hline & $(0.001)$ & $(0.001)$ & $(0.002)$ & $(0.001)$ & $(0.001)$ & $(0.001)$ \\
\hline \multirow[t]{2}{*}{ Pill Mill } & 0.002 & 0.001 & -0.002 & -0.001 & 0.004 & 0.003 \\
\hline & $(0.003)$ & $(0.002)$ & $(0.004)$ & $(0.002)$ & $(0.004)$ & $(0.002)$ \\
\hline \multicolumn{7}{|l|}{$\begin{array}{l}\text { B. Model with Baseline } \\
\text { Opioid Interactions }\end{array}$} \\
\hline \multirow[t]{2}{*}{ Modern PDMP } & $0.002 *$ & 0.001 & 0.003 & 0.001 & $0.002^{*}$ & 0.001 \\
\hline & $(0.001)$ & $(0.001)$ & $(0.002)$ & $(0.001)$ & $(0.001)$ & $(0.001)$ \\
\hline \multirow[t]{2}{*}{ Pill Mill } & 0.002 & 0.001 & -0.001 & -0.000 & 0.003 & $0.002 *$ \\
\hline & $(0.002)$ & $(0.001)$ & $(0.003)$ & $(0.001)$ & $(0.002)$ & $(0.001)$ \\
\hline Mean of Dependent Variable & 0.107 & 0.066 & 0.104 & 0.051 & 0.109 & 0.075 \\
\hline Number of Observations & 223,528 & 223,484 & 81,515 & 83,059 & 142,013 & 140,425 \\
\hline
\end{tabular}

Notes: The unit of observation is the state-year-group (age-by female). All regression models include state and year fixed effects, dummy variables for each year of age and dummy variables for race/ethnicity (non-Hispanic white, non-Hispanic black, Hispanic, and non-Hispanic other), interactions of the race categories and year effects. Panel B, adds the interactions between baseline opioid sales and year effects. All regressions are weighted by the number of individuals in a group. Standard errors in parentheses. Standard errors were constructed allowing for non-independence (clustering) within state. $* 0.05<\mathrm{p}$-value $\leq 0.10, * * \mathrm{p}$-value $\leq 0.05$ 
Appendix Table 6: Estimates of Effects of State Polices on Probability of Married and Living with Spouse, 2002 to 2016 Sample of Persons with 12 or Fewer Years of Education

\begin{tabular}{|c|c|c|c|c|c|c|}
\hline & \multicolumn{2}{|c|}{ All Ages } & \multicolumn{2}{|c|}{ Age 18-34 } & \multicolumn{2}{|c|}{ Age 35-64 } \\
\hline & Females & Males & Females & Males & Females & Males \\
\hline \multicolumn{7}{|l|}{ A. Basic Model } \\
\hline Modern PDMP & $\begin{array}{l}-0.004^{*} \\
(0.002)\end{array}$ & $\begin{array}{l}-0.000 \\
(0.002)\end{array}$ & $\begin{array}{c}-0.008 * * \\
(0.003)\end{array}$ & $\begin{array}{l}-0.006^{* *} \\
(0.002)\end{array}$ & $\begin{array}{l}-0.001 \\
(0.002)\end{array}$ & $\begin{array}{c}0.002 \\
(0.003)\end{array}$ \\
\hline Pill Mill & $\begin{array}{c}-0.005^{* *} \\
(0.002)\end{array}$ & $\begin{array}{c}-0.007 * * \\
(0.002)\end{array}$ & $\begin{array}{l}-0.004 \\
(0.004)\end{array}$ & $\begin{array}{c}-0.006^{* *} \\
(0.003)\end{array}$ & $\begin{array}{l}-0.005 \\
(0.003)\end{array}$ & $\begin{array}{c}-0.007 * * \\
(0.003)\end{array}$ \\
\hline \multicolumn{7}{|l|}{$\begin{array}{l}\text { B. Model with Baseline } \\
\text { Opioid Interactions }\end{array}$} \\
\hline Modern PDMP & $\begin{array}{l}-0.006^{* *} \\
(0.002)\end{array}$ & $\begin{array}{l}-0.003 \\
(0.002)\end{array}$ & $\begin{array}{c}-0.009 * * \\
(0.003)\end{array}$ & $\begin{array}{c}-0.006^{* *} \\
(0.002)\end{array}$ & $\begin{array}{c}-0.004^{* *} \\
(0.002)\end{array}$ & $\begin{array}{l}-0.001 \\
(0.002)\end{array}$ \\
\hline Pill Mill & $\begin{array}{l}-0.003 \\
(0.002)\end{array}$ & $\begin{array}{c}-0.006^{* *} \\
(0.003)\end{array}$ & $\begin{array}{l}-0.004 \\
(0.004)\end{array}$ & $\begin{array}{c}-0.006^{* *} \\
(0.003)\end{array}$ & $\begin{array}{l}-0.004 \\
(0.002)\end{array}$ & $\begin{array}{l}-0.006^{*} \\
(0.003)\end{array}$ \\
\hline Mean of Dependent Variable & 0.463 & 0.458 & 0.317 & 0.254 & 0.547 & 0.579 \\
\hline Number of Observations & 223,528 & 223,484 & 81,515 & 83,059 & 142,013 & 140,425 \\
\hline
\end{tabular}

Notes: The unit of observation is the state-year-group (age-by female). All regression models include state and year fixed effects, dummy variables for each year of age and dummy variables for race/ethnicity (non-Hispanic white, non-Hispanic black, Hispanic, and non-Hispanic other), interactions of the race categories and year effects. Panel B, adds the interactions between baseline opioid sales and year effects. All regressions are weighted by the number of individuals in a group. Standard errors in parentheses. Standard errors were constructed allowing for non-independence (clustering) within state. $* 0.05<\mathrm{p}$-value $\leq 0.10, * * \mathrm{p}$-value $\leq 0.05$ 
Appendix Table 7: Estimates of Effects of State Polices on Probability of Any Cognitive or Ambulatory Difficulty, 2002 to 2016 Sample of Persons with 12 or Fewer Years of Education

\begin{tabular}{|c|c|c|c|c|c|c|}
\hline & \multicolumn{2}{|c|}{ All Ages } & \multicolumn{2}{|c|}{ Age 18-34 } & \multicolumn{2}{|c|}{ Age 35-64 } \\
\hline & Females & Males & Females & Males & Females & Males \\
\hline \multicolumn{7}{|l|}{ A. Basic Model } \\
\hline Modern PDMP & $\begin{array}{l}-0.003 \\
(0.002)\end{array}$ & $\begin{array}{c}0.001 \\
(0.002)\end{array}$ & $\begin{array}{l}-0.001 \\
(0.001)\end{array}$ & $\begin{array}{c}0.001 \\
(0.001)\end{array}$ & $\begin{array}{l}-0.004 \\
(0.003)\end{array}$ & $\begin{array}{l}-0.000 \\
(0.002)\end{array}$ \\
\hline Pill Mill & $\begin{array}{c}0.000 \\
(0.003)\end{array}$ & $\begin{array}{l}-0.001 \\
(0.002)\end{array}$ & $\begin{array}{l}-0.001 \\
(0.001)\end{array}$ & $\begin{array}{l}-0.002 \\
(0.001)\end{array}$ & $\begin{array}{c}0.001 \\
(0.004)\end{array}$ & $\begin{array}{l}-0.001 \\
(0.003)\end{array}$ \\
\hline \multicolumn{7}{|l|}{$\begin{array}{l}\text { B. Model with Baseline } \\
\text { Opioid Interactions }\end{array}$} \\
\hline Modern PDMP & $\begin{array}{l}-0.000 \\
(0.002)\end{array}$ & $\begin{array}{l}0.003^{*} \\
(0.001)\end{array}$ & $\begin{array}{l}-0.000 \\
(0.001)\end{array}$ & $\begin{array}{c}0.002 \\
(0.001)\end{array}$ & $\begin{array}{c}0.000 \\
(0.002)\end{array}$ & $\begin{array}{c}0.003 \\
(0.002)\end{array}$ \\
\hline Pill Mill & $\begin{array}{l}-0.001 \\
(0.002)\end{array}$ & $\begin{array}{l}-0.002 \\
(0.002)\end{array}$ & $\begin{array}{l}-0.002 \\
(0.002)\end{array}$ & $\begin{array}{l}-0.002 \\
(0.002)\end{array}$ & $\begin{array}{c}0.000 \\
(0.002)\end{array}$ & $\begin{array}{l}-0.001 \\
(0.002)\end{array}$ \\
\hline Mean of Dependent Variable & 0.188 & 0.182 & 0.108 & 0.113 & 0.234 & 0.223 \\
\hline Number of Observations & 223,528 & 223,484 & 81,515 & 83,059 & 142,013 & 140,425 \\
\hline
\end{tabular}

Notes: The unit of observation is the state-year-group (age-by female). All regression models include state and year fixed effects, dummy variables for each year of age and dummy variables for race/ethnicity (non-Hispanic white, non-Hispanic black, Hispanic, and non-Hispanic other), interactions of the race categories and year effects. Panel B, adds the interactions between baseline opioid sales and year effects. All regressions are weighted by the number of individuals in a group. Standard errors in parentheses. Standard errors were constructed allowing for non-independence (clustering) within state. $* 0.05<\mathrm{p}$-value $\leq 0.10, * * \mathrm{p}$-value $\leq 0.05$ 
Appendix Figure 1: Event Study Coefficients of the Effect of State Opioid Policies on Mortality Rates of All Causes 2002-2016

A. Females 18-34
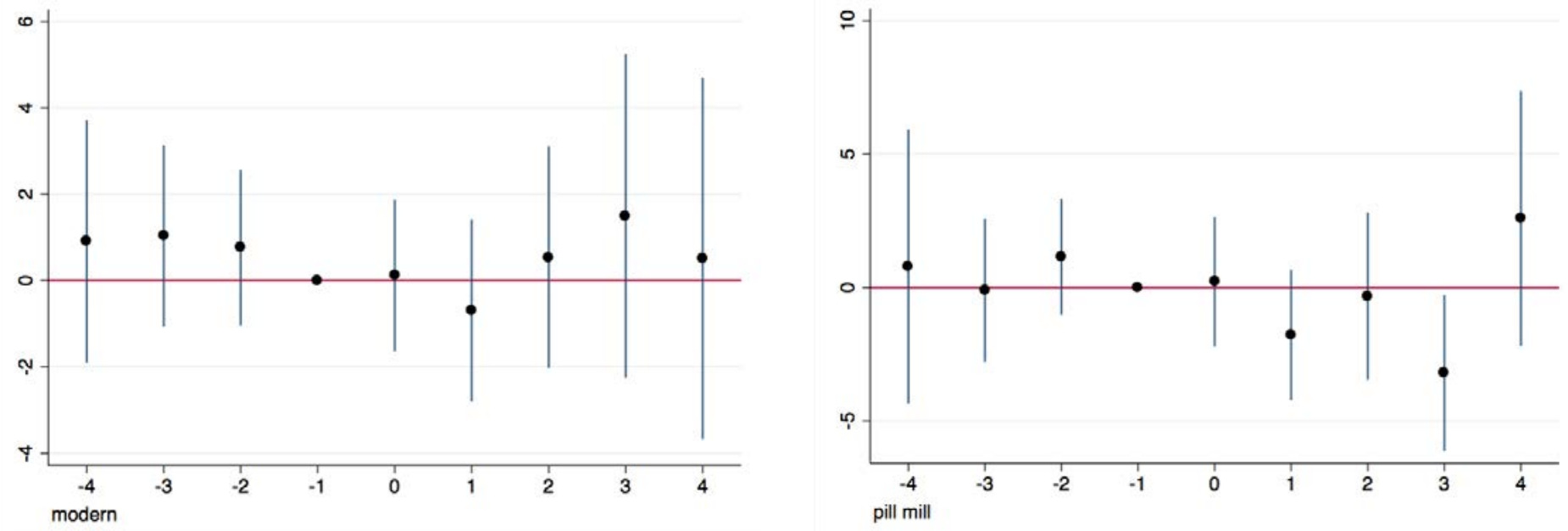

B. Males 18-34
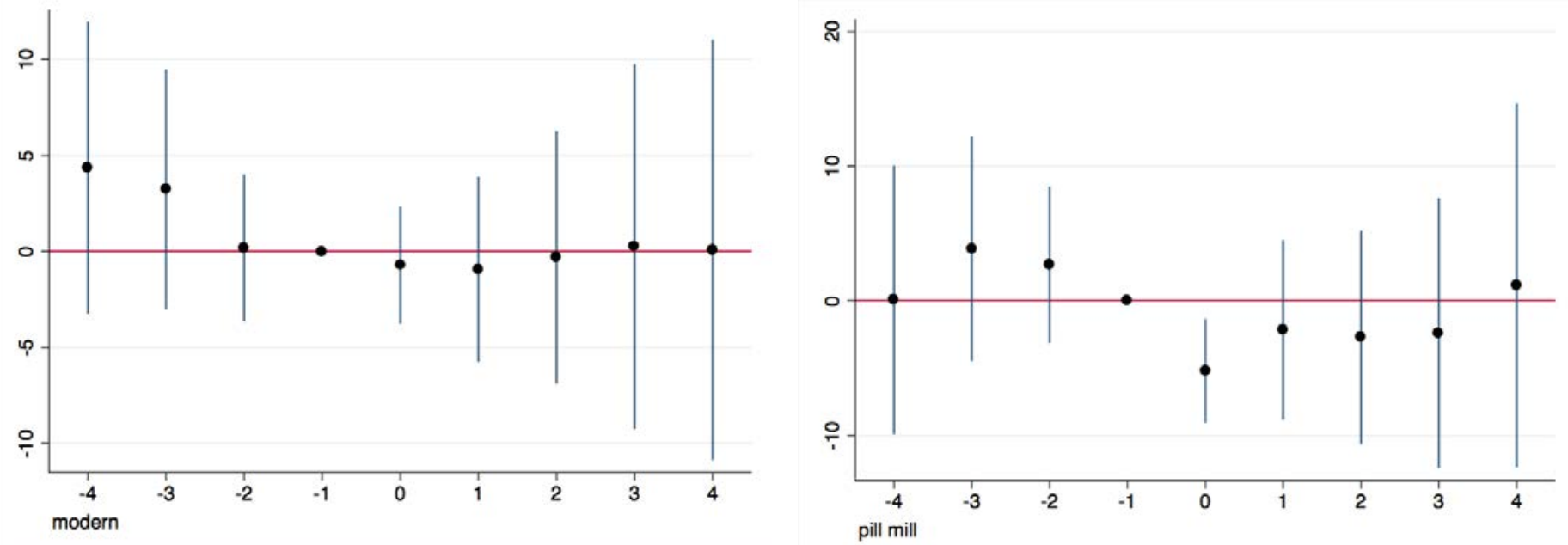
Appendix Figure 2: Event Study Coefficients of the Effect of State Opioid Policies on Mortality Rates of All Causes 2002-2016

A. Females 35-64
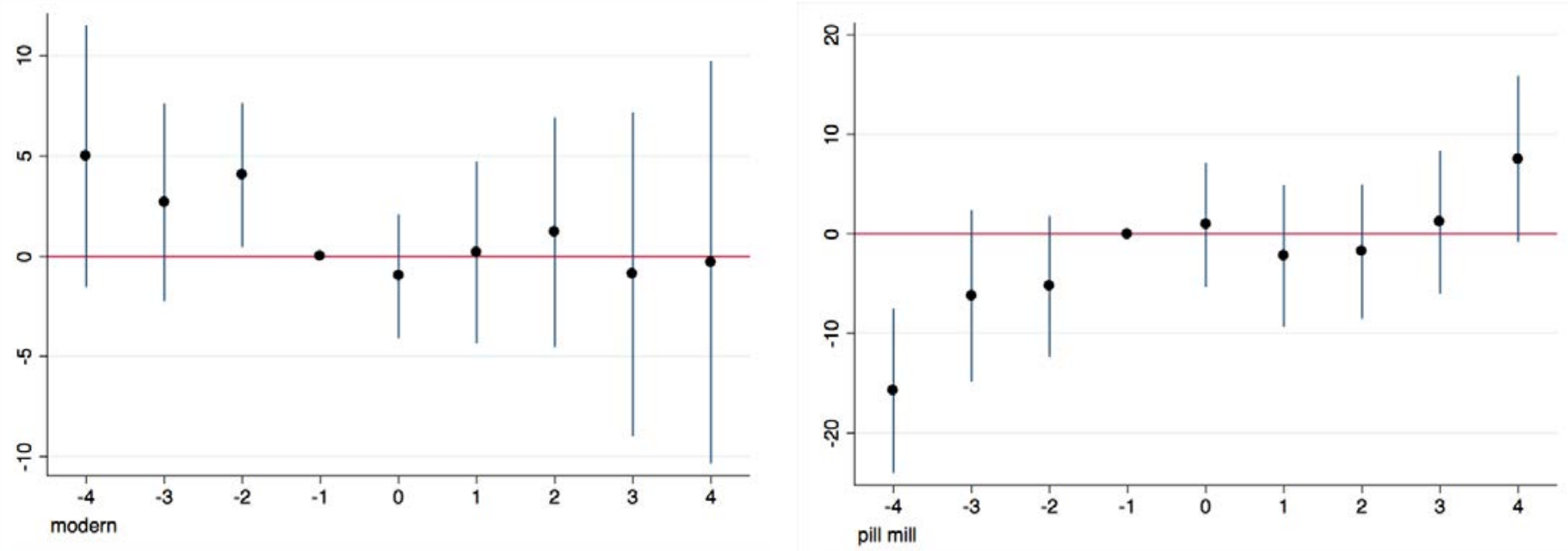

B. Males 35-64
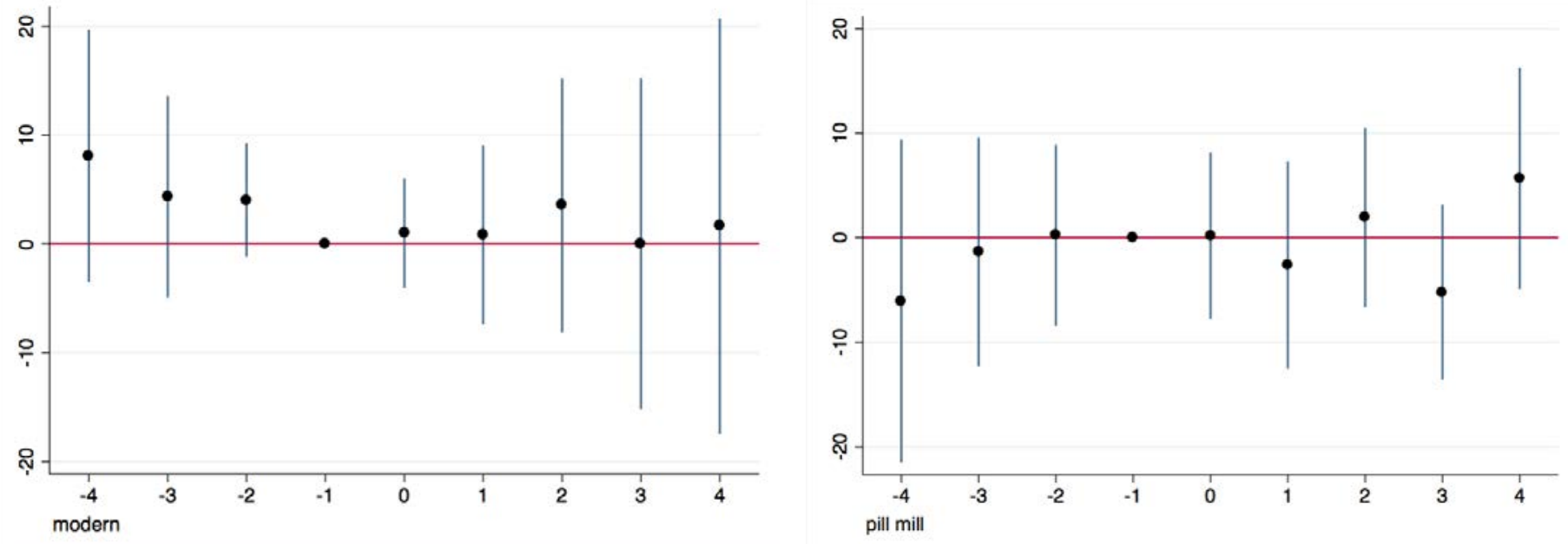
Appendix Figure 3: Event Study Coefficients of the Effect of State Opioid Policies on Mortality Rates of Drug Related Causes 2002-2016

A. Females 18-34
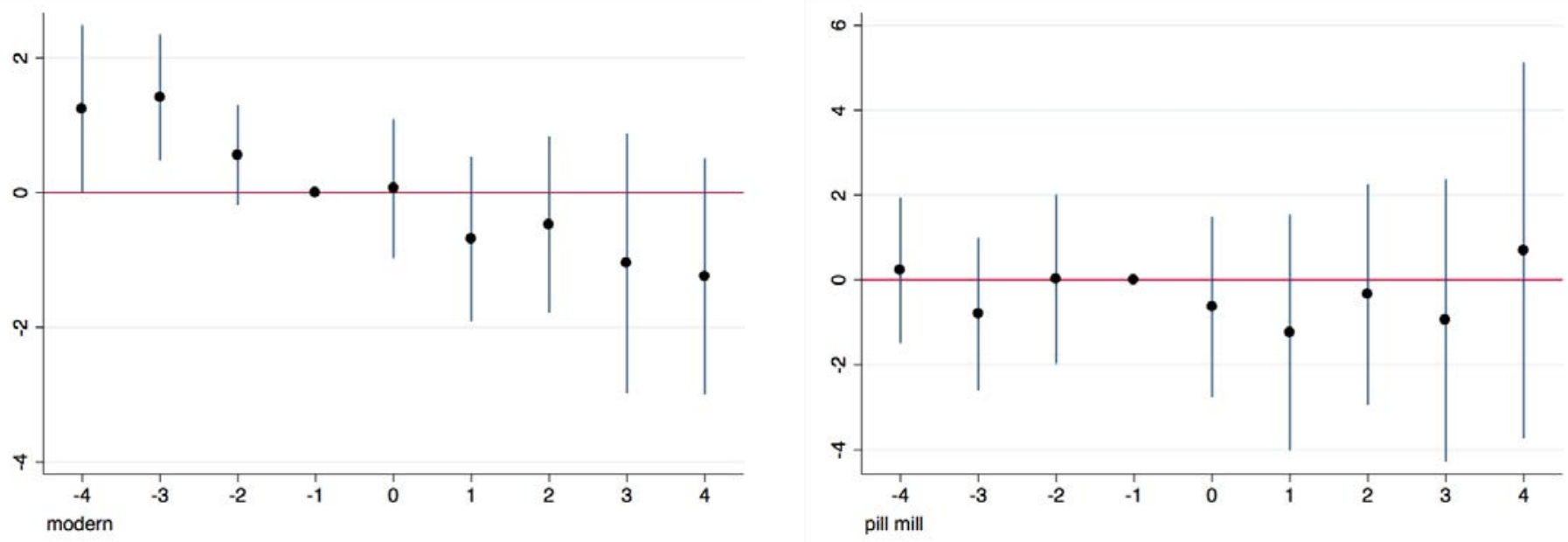

B. Males 18-34
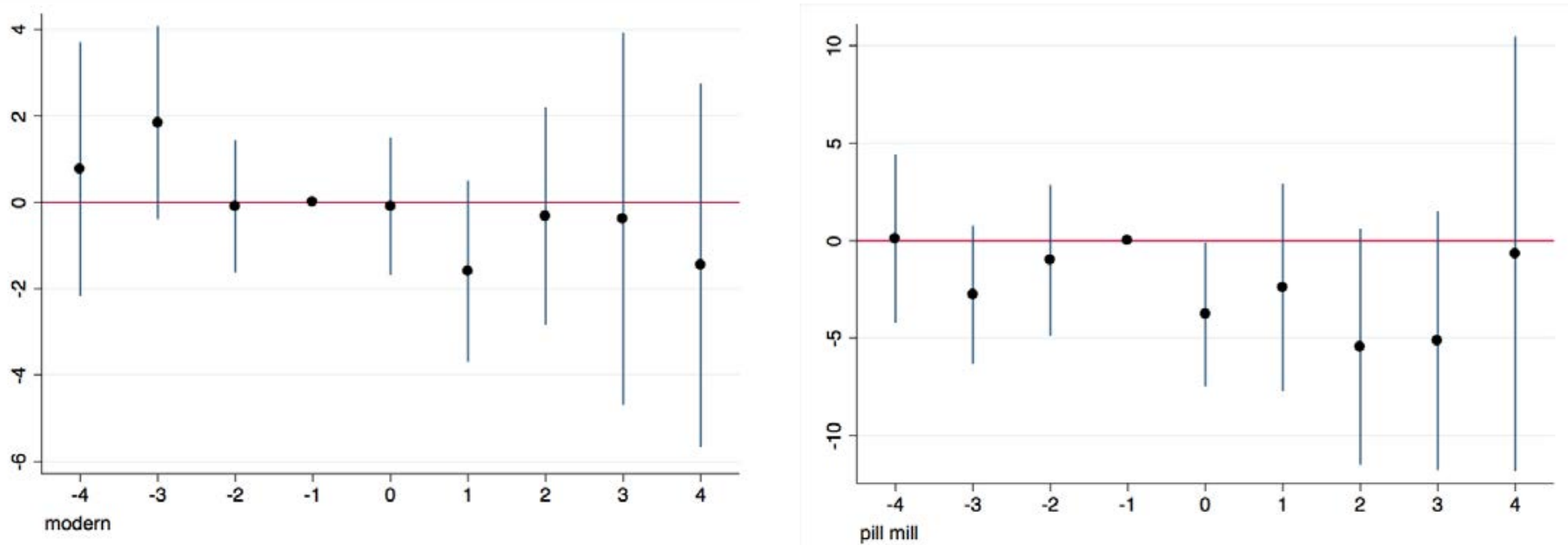
Appendix Figure 4: Event Study Coefficients of the Effect of State Opioid Policies on Mortality Rates of Drug Related Causes 2002-2016

A. Females 35-64
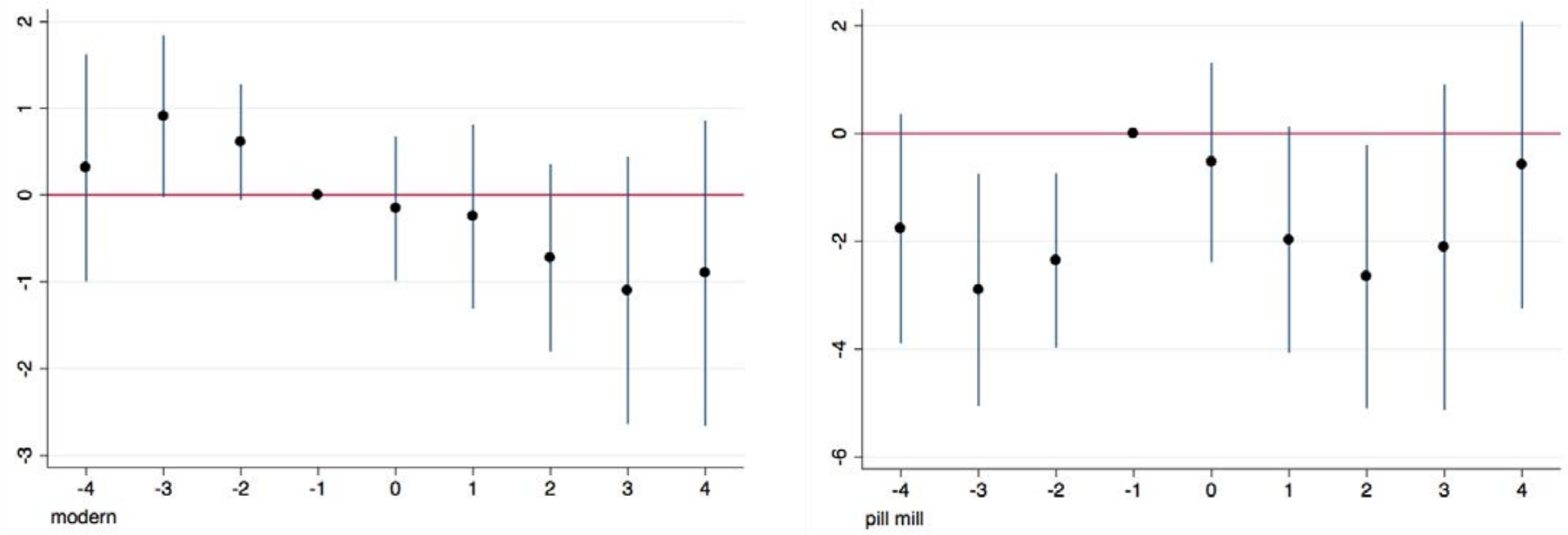

B. Males 35-64
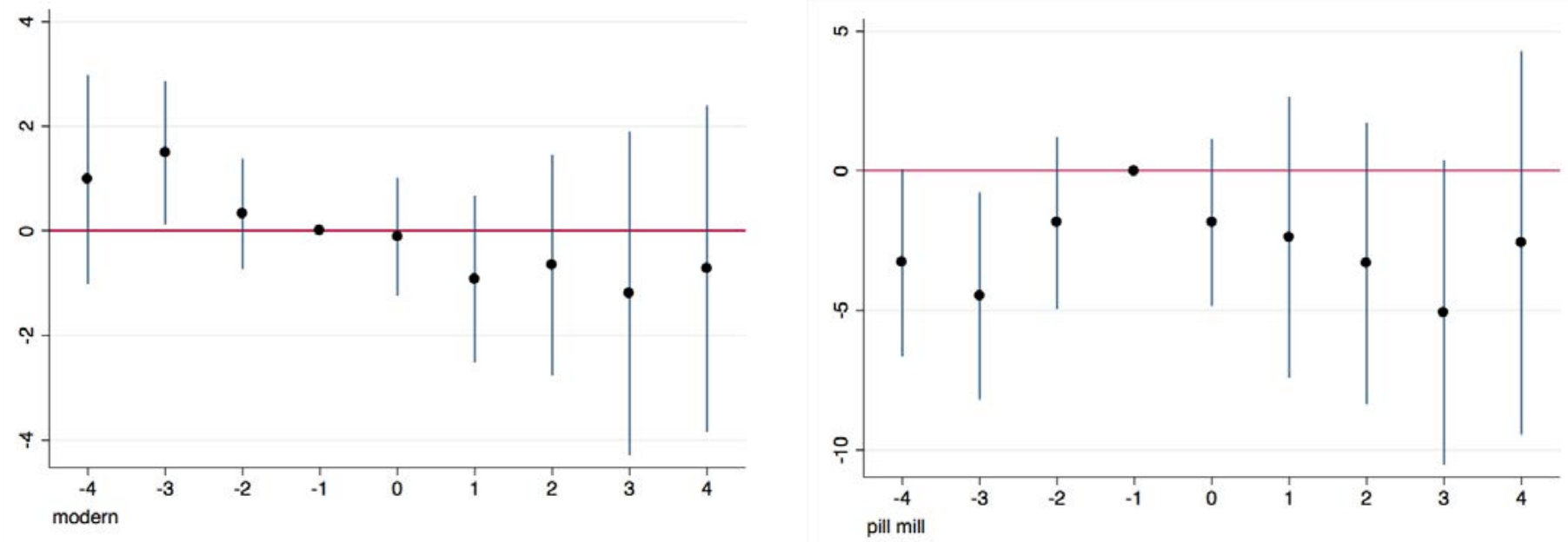
Appendix Figure 5: Event Study Coefficients of the Effect of State Opioid Policies on Probability of Being Employed at Time of Survey 2002-2016

A. Females $18-34$
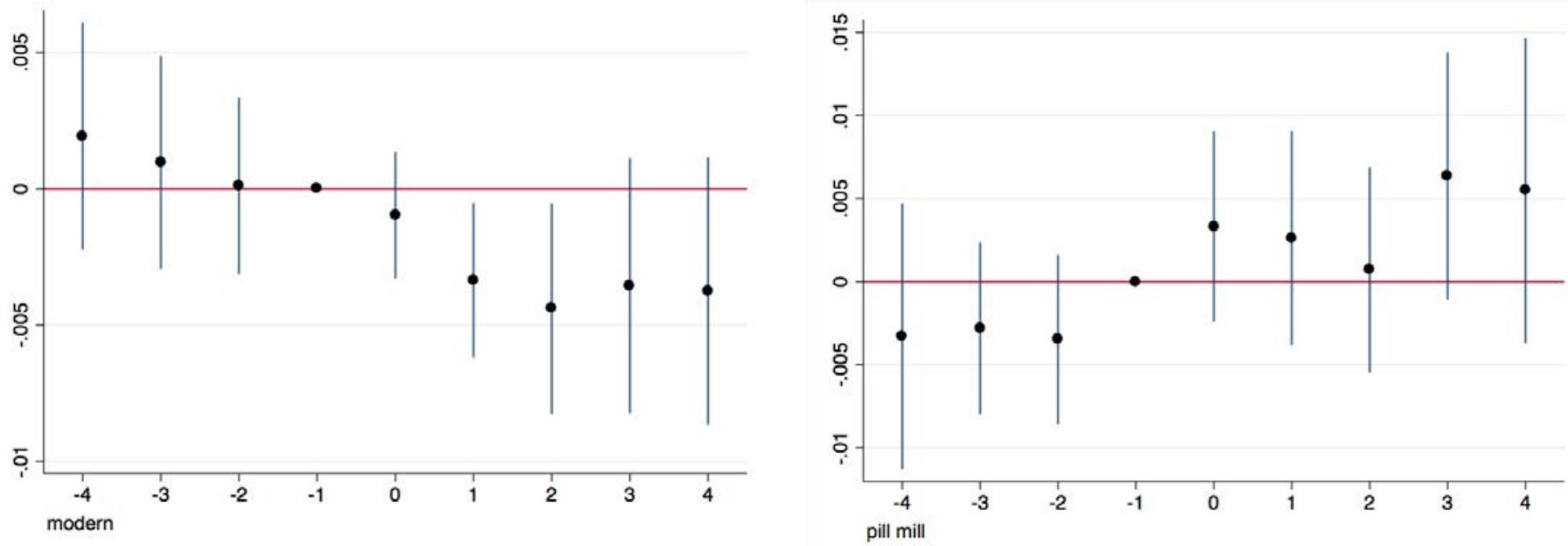

B. Males 18-34
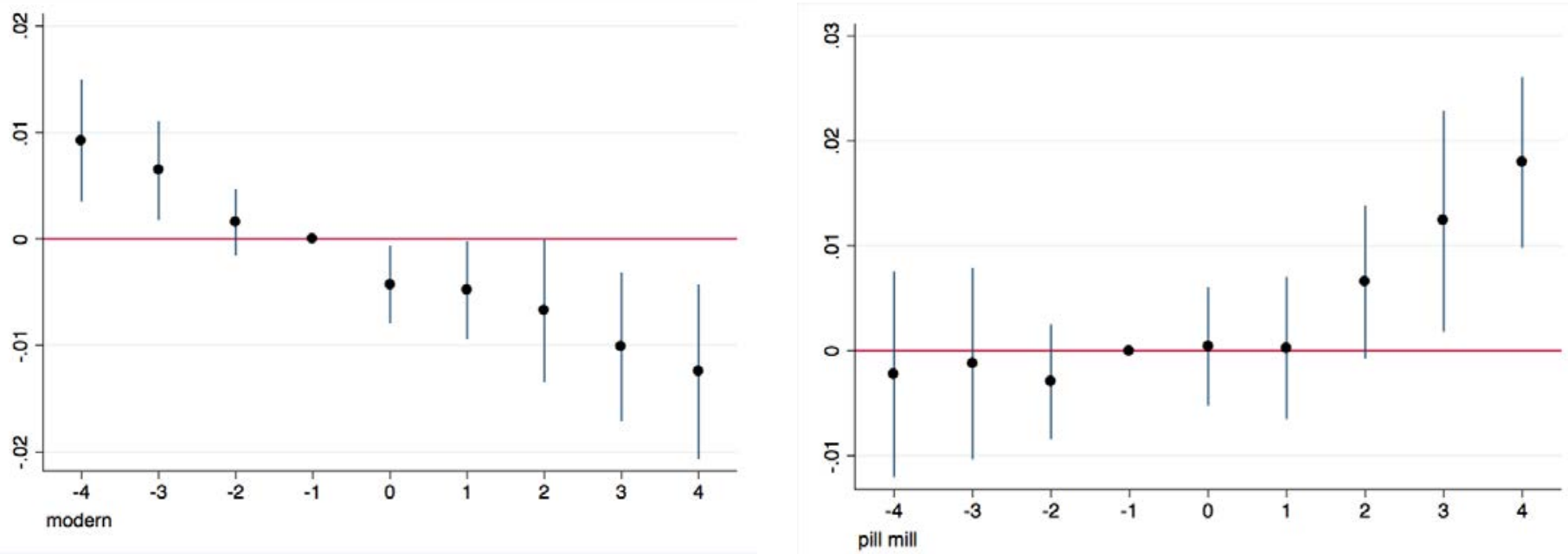
Appendix Figure 6: Event Study Coefficients of the Effect of State Opioid Policies on Probability of Being Employed at Time of Survey 2002-2016

A. Females 35-64
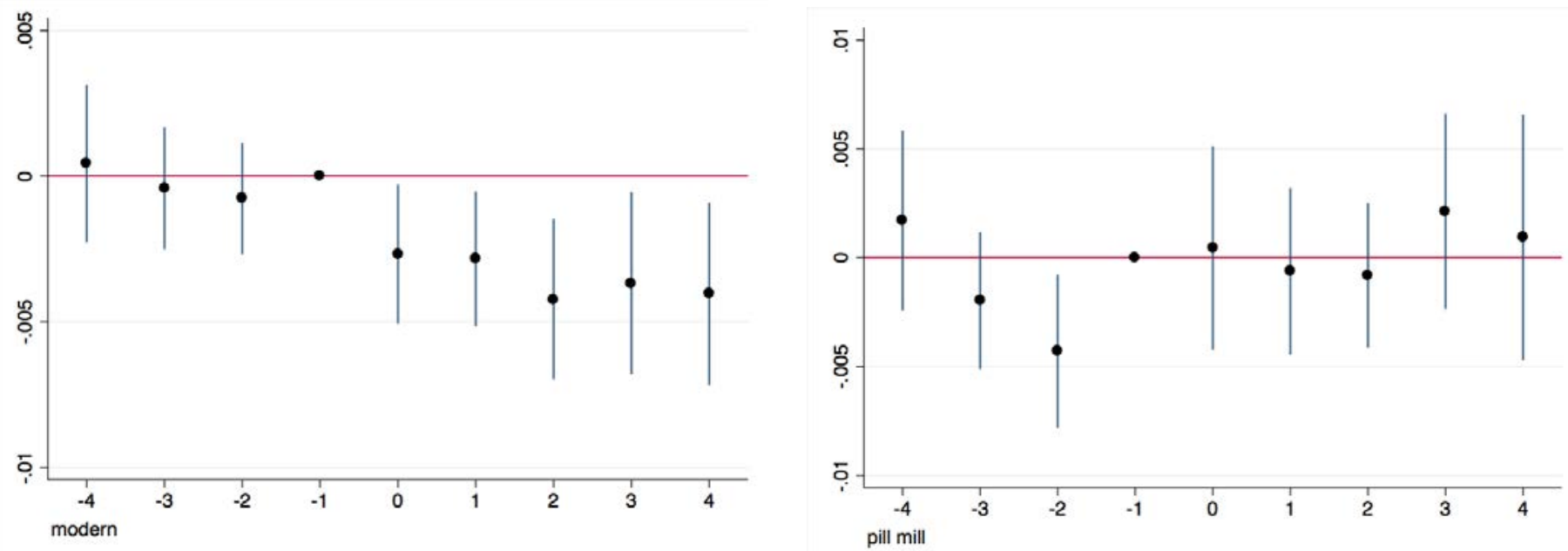

B. Males 35-64
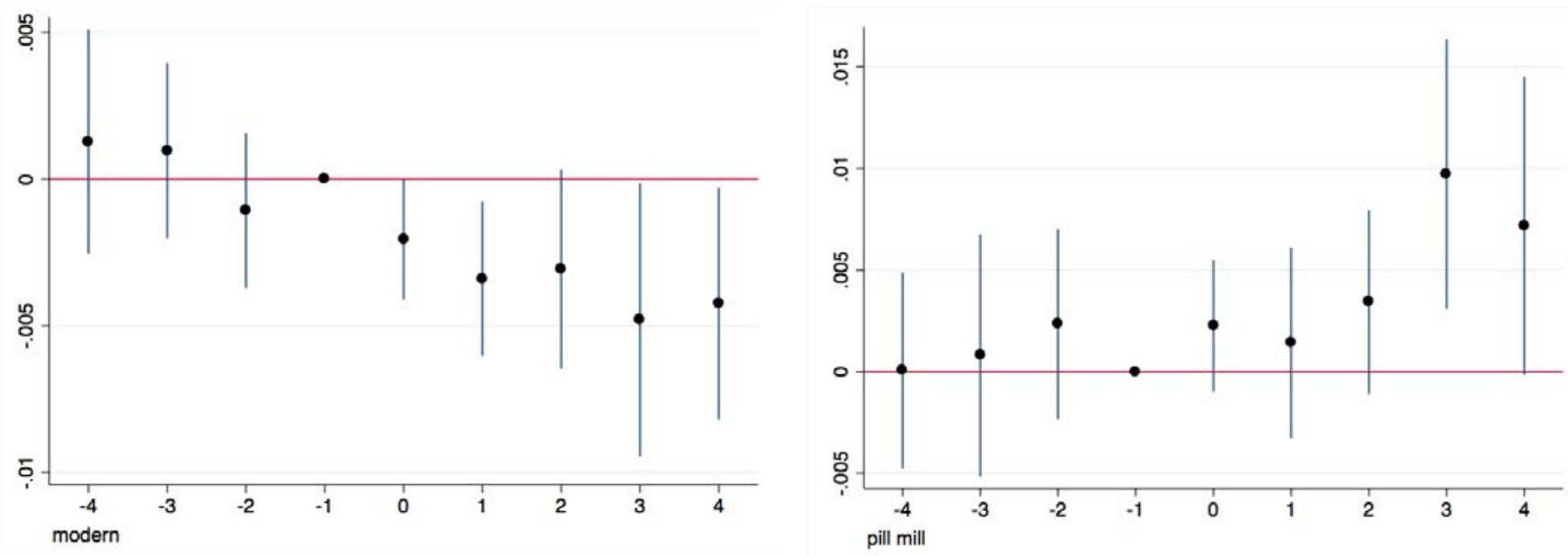